Economía Teoría y PrÁctica Nueva Época, número 48, enero-junio 2018, pp. 39-74, http://dx.doi.org/10.24275/ETYPUAM/NE/482018/Reyes

\title{
Exploración, explotación y spillovers de conocimientos en la industria automotriz. El caso de Delphi México, un estudio de patentes*
}

\section{Exploration, Exploitation and Spillovers of Knowledge in the Automotive Industry. The Case of Delphi Mexico, a Patent Analysis}

Juan Reyes Álvarez**

\begin{abstract}
RESUMEN
La industria automotriz en México es vista como generadora de derramas económicas además de tecnológicas. La proveedora Delphi ha servido a cierta literatura para describir una generación de maquiladoras basadas en conocimiento. Este trabajo tiene como objetivo cuestionar si dicha empresa ha generado spillovers tecnológicos en el país. Para lo anterior, se retoman los conceptos de exploración y explotación de conocimientos, analizando las patentes de la empresa y enfocándose en aquellas que incorporan inventores mexicanos.
\end{abstract}

Palabras clave: Spillovers tecnológicos, estrategia de empresas transnacionales, inventores, patentes.

Clasificación JEL: O32, O33, O34.

\section{Abstract}

The automotive industry in Mexico is thought as generating economic spillovers but also technological spillovers. The supplier Delphi has served as an example to describe a generation of knowledge-based maquiladoras in some literature. In this regard, this paper aims to question whether the firm has generated technological spillovers in Mexico. For this, the concepts of exploration and exploitation of knowledge are retaken, analyzing patents the company and focusing on incorporating Mexican inventors.

Keywords: Exploration, exploitation, patents.

JEL Classification: O32, O33, O34.

* Fecha de recepción: 25-04-2016. Fecha de aprobación: 11-10-2017.

** Benemérita Universidad Autónoma de Puebla. Correo: jra2405@gmail.com. ORCID: 00000002-0416-4411 


\section{INTRODUCCIÓN}

La industria automotriz en México se ha pensado como uno de los principales mecanismos para elevar el empleo y la generación de derramas económicas en el país, así, dicha industria se ha convertido en centro de la política económica; esto resulta evidente en programas como el de la Industria Maquiladora de Exportación (IME), exención de impuestos de gobiernos locales y federales, así como la creación de unidades educativas públicas focalizadas para el servicio de los generadores de dicha inversión (Covarrubias y Arteaga-García, 2015).

En la última década ha habido un auge en la industria automotriz, en torno a ella, gira una larga cadena de empresas armadoras y de proveeduría, principalmente de origen extranjero. Algunos autores han afirmado que se ha gestado una generación de empresas maquiladoras en México (Carrillo y Hualde, 1997a; 1997b; Carrillo y Lara, 2004; Lara, 2000). Sin embargo, aun cuando existe una sustancial generación de empleos, creación de centros de servicios tecnológicos y patentes en México por parte de la industria, no se ha definido si ha tenido un efecto de arrastre o creación de spillovers de conocimientos en México. Para saber lo anterior, este trabajo se centrará en el análisis de indicadores de patentes, bajo el uso de los conceptos de exploración y explotación, que permiten un marco de análisis más amplio que el de spillovers.

El siguiente trabajo cuestiona las afirmaciones mencionadas, para lo cual aborda las siguientes preguntas: 1) ¿Delphi ha provocado spillovers de conocimientos en México?; 2) ¿Qué tipo de estrategia sigue la empresa Delphi para el aprovechamiento de los conocimientos tecnológicos y sus spillovers?; 3) ¿Qué lugar ocupan los recursos humanos (inventores) y empresariales en México en la estrategia de Delphi? Para responder a lo anterior, la investigación que se presentará será de tipo cuantitativo, se retoman los conceptos de exploración, explotación y spillovers de conocimientos y el uso de indicadores basados en patentes.

El siguiente trabajo se divide en cinco apartados que se describen a continuación: 1) el primer apartado aborda la importancia de por qué estudiar a Delphi, se establece su entorno internacional y los estudios recientes de los que ha sido objeto, específicamente en el caso de México; 2) en el siguiente, se describen los conceptos de exploración, explotación y spillovers de conocimientos y su relevancia para ser incorporados al análisis de la estrategia de la empresa con base tecnológica; 3) en el tercero, se establecen los insumos y herramientas (metodológicas) para operar los conceptos citados, por medio del uso de indicadores de patentes; 4) en el cuarto apartado se presentan resultados, en el que se hace énfasis en el aprovechamiento de Delphi y otras empresas de los conocimientos 
tecnológicos de ésta y la presencia o ausencia de spillovers para México; 5) consideraciones finales.

\section{Relevancia de DelPhi en MéXico}

Delphi es considerada importante para México por la capacidad de generación de empleos y desarrollo tecnológico con los que cuenta (plasmado en sus centros técnicos, personal calificado y sus patentes de inventores nacionales), esto ha motivado a afirmar que dicha empresa es un modelo y puede representar un hito en la manufactura en México.

\section{I.1. Delphi y su relevancia económica}

Las empresas armadoras de autos y productoras de autopartes han tenido un auge especial en México, hoy en 10 de los 32 estados mexicanos existe presencia de armadoras, hay siete corporativos internacionales con producción en 14 plantas en el país (sólo considerando la producción de autos ligeros), con el 84 por ciento de la producción para el mercado externo (ProMexico, 2013) ${ }^{1}$. Ante esto, una gran cadena de proveeduría se ha desarrollado en todo el país. Entre esa lista destaca Delphi Corporation, por su generación de empleo y destacada presencia de plantas en varios estados y por ser una de las primeras en instalar un Centro Técnico, con un número considerable de personal con alta capacitación. Por lo expuesto, se matizará a continuación la situación actual de Delphi, parte de su historia, la importancia internacional en el traslado de sus operaciones a México, además del debate en torno a ser considerada como ejemplo de una nueva generación de maquilas.

La empresa Delphi Corporation (hasta 2002 la denominación era Delphi Automotive System) es una subsidiaria de la armadora de autos General Motors (GMC), de la cual se separa totalmente en 1995, específicamente es proveedora de autopartes nivel 1 (tier 1), de GMC. Por otro lado, su lista de clientes llega a 25 armadoras de todo el mundo. Si bien, su principal cliente en 2015 era GMC, con 14 por ciento de sus ventas, otros clientes importantes según sus ventas son (ver cuadro 1): VW 8 por ciento, Ford 6 por ciento, Daimler ( 5 por ciento), Shangai 5 por ciento, entre las más importantes (Delphi, 2015).

${ }^{1}$ En México se encuentran actualmente 18 productores de equipo original en el país (para auto ligero y pesado) y en los próximos dos años se esperan que entren dos nuevas marcas de lujo: Audi (Corporativo VW) y BMW. 
Cuadro 1. Ventas a principales clientes de Delphi. Porcentaje respecto al total de las ventas anuales

\begin{tabular}{|c|c|c|c|c|c|}
\hline Empresa & 2009 & 2010 & 2013 & 2014 & 2015 \\
\hline GMC & 20 & 21 & 17 & 17 & 14 \\
\hline VW & 7 & 8 & 10 & 10 & 8 \\
\hline Ford & $\mathrm{nd}^{*}$ & 9 & 6 & 6 & 6 \\
\hline Daimler & 6 & 6 & 6 & 6 & 5 \\
\hline Shanghai GM & 4 & 4 & 5 & 5 & 5 \\
\hline Hyundai & 4 & 3 & 3 & 4 & 4 \\
\hline Geely & $\mathrm{nd}^{*}$ & $n d^{*}$ & 3 & 3 & 3 \\
\hline$A B$ Volvo & $\mathrm{nd}^{*}$ & $\mathrm{nd}^{*}$ & $n d^{*}$ & $n d^{*}$ & 2 \\
\hline PSA Peugeot-Citroën & 5 & 5 & 4 & 5 & $\mathrm{nd}^{*}$ \\
\hline Toyota & $\mathrm{nd}^{*}$ & 3 & 3 & 2 & $\mathrm{nd}^{*}$ \\
\hline Fiat & 4 & 3 & 3 & $n d^{*}$ & $\mathrm{nd}^{*}$ \\
\hline Renault & 5 & 4 & $\mathrm{nd}^{*}$ & $n d^{*}$ & $\mathrm{nd}^{*}$ \\
\hline Resto empresas & 45 & 34 & 40 & 42 & $\mathrm{nd}^{*}$ \\
\hline
\end{tabular}

*nd: no hay datos.

Fuente: Elaboración propia con base en Delphi (2010, 2013, 2014, 2015 y 2016).

La producción de Delphi hasta 2014 giraba alrededor de cuatro segmentos de productos: 1) arquitectura eléctrica y electrónica (AEE); 2) sistemas de propulsión (SP); 3) electrónicos y seguridad (ES); 4) sistema térmicos (ST) ${ }^{2}$. El modelo de negocios incluye la investigación y desarrollo en los productos mencionados y las posibles aplicaciones tecnológicas no solamente dentro de la industria automotriz.

Según datos de la Oficina de Marcas y Patentes de Estados Unidos (USPTO por sus siglas en inglés, 2015), en relación con su esfuerzo inventivo, Delphi ha registrado 5,119 patentes en Estados Unidos (2014), en 6,022 subclases tecnológicas ${ }^{3}$. De esas subclases sólo una tiene el 10.4 por ciento de las patentes: el mecanismo para operar las válvulas de presión. Dicho proceso es el regulador del paso de los gases que hacen mover el automóvil. Después de esta subclase le siguen muy por debajo con menos del 5 por ciento cada una las 6,021 restantes subclases tecnológicas.

En lo que respecta a su situación económica, Delphi ha presentado marcados altibajos durante su vida productiva, debido principalmente a la declaración de bancarrota en 2009 de su principal cliente GMC. En el cuadro 2, se presentan las ventas netas (VN) de Delphi en el periodo de 2005 a 2014 a nivel mundial, mientras que en 2005 las vN eran de 19,922 millones de dólares, para 2008 presentan una

${ }^{2}$ El segmento de sistemas térmicos fue vendido a MAHLE GmbH en 2015.

${ }^{3}$ Una patente puede ser registrada en una o más subclases tecnológicas que pueden obedecer a subclases no emparentadas. 
caída sustancial llegando a 16,088. Lo que representó 13.92 por ciento menos respecto al año anterior. De hecho, en 2010 la caída fue mucho mayor, las ventas llegaron a 10,615 millones. Tal fue el impacto que de 2009 a 2014 las VN reportadas apenas alcanzan los valores de 2009.

Esta problemática se observa también en el empleo en el periodo mencionado (ver cuadro 2). En 2005 el número de empleados a nivel mundial (ENM) era de 184,500 personas, el ENM se mantuvo a la baja año tras año hasta 2010 cuando llegó a 99,700 empleados: 43.19 por ciento menos trabajadores que en 2005. Mientras que en el periodo 2010 a 2014 se observa un crecimiento sustancial de 60.48 por ciento en el empleo. El ENM, muestra su mayor incremento de 2013 a 2014, pasando de 117,000 empleados a 160,000 según los reportes de la misma empresa, lo anterior muestra una recuperación por parte de ésta.

Un dato adicional de esa recuperación son las locaciones financieras de las que es propietaria. En 2010 tenía 97 locaciones manufactureras, (número independiente de las que además rentaba para estas actividades) en 32 países, mientras que para 2015 eran ya 126. El cuadro 3 muestra el número de estas propiedades respecto a su localización geográfica (4 regiones) y a los cuatro segmentos de negocio de la empresa. El mayor número de plantas en 2015 se encuentran en la región Europa-Este Medio (49), seguidas de Norteamérica (37) y Asia Pacífico (33), por último Sudamérica (7). Con relación a los segmentos de producción 78 de las 126 (62 por ciento) se centran en AEE, seguido con las locaciones de SP con 21, ES con 16 y sT con 11 plantas respectivamente.

Las dos regiones donde se presentó mayor crecimiento de propiedades son Asia Pacífico y Norteamérica con 11 y 12 locaciones más de 2010 a 2015, destinadas específicamente al segmento de AEE. Como se aprecia, existe una mayor especialización en lo que respecta al segmento AEE, esto se expresa también en las vN de Delphi, de las cuales 48 por ciento corresponden a dicho segmento, seguidas de SP con 27 por ciento, TS y ST con 17 y 9 por ciento respectivamente.

Por lo expuesto arriba, la situación económica se ha recuperado (niveles de vN alcanzados, número de empleados y adquisición de nuevas plantas), esto ha ido en paralelo con una reorganización de la empresa. A partir de la declaración de bancarrota de GMC en 2009, Delphi fue paulatinamente cerrando 21 de 29 plantas en Estados Unidos, moviendo la producción de dichas plantas, principalmente a México. La misma empresa reconoce que fue por las facilidades que México ofrece en relación con programas que incentivan la Industria Maquiladora de Exportación (IME).

La historia de Delphi en México no es reciente, se remonta a 1978 cuando inicia con dos plantas en los estados de Chihuahua y Tamaulipas. Después de 37 años la empresa cuenta con 50 plantas en México, en 2013 contaba con más de 54,000 empleados (Gutiérrez, 2013). Lo anterior contrasta con los 5,000 (4.2 por 
ciento de los ENM) que en el mismo año laboraban en Estados Unidos, el número de empleados en México representó en 2013 el 46 por ciento del ENM según lo reportado por la empresa. En este sentido, se destaca la importancia estratégica en la región para Delphi específicamente para el caso de México.

Cuadro 2. Ventas netas y empleados a nivel mundial de Delphi (2005-2014)**

\begin{tabular}{|c|c|c|c|c|c|c|}
\hline Año & $\begin{array}{l}\text { Ventas netas (vN) } \\
\text { Millones de dólares }\end{array}$ & $\begin{array}{l}\text { Tasa de crecimiento } \\
\text { anual vn }(\%)\end{array}$ & Índice vN* & $\begin{array}{l}\text { Empleados a nivel } \\
\text { mundial (ENM) }\end{array}$ & $\begin{array}{l}\text { Tasa de crecimien- } \\
\text { to anual enM (\%) }\end{array}$ & Índice ENM * \\
\hline 2001 & $\mathrm{Nd}$ & $\mathrm{Nd}$ & $\mathrm{Nd}$ & 193,000 & $\mathrm{Nd}$ & $\mathrm{Nd}$ \\
\hline 2005 & $\$ 19,922$ & & 100 & 184,500 & & 100 \\
\hline 2006 & $\$ 19,329$ & -2.98 & 97.02 & 171,400 & -7.1 & 92.9 \\
\hline 2007 & $\$ 19,526$ & 1.02 & 98.01 & 169,500 & -1.11 & 91.87 \\
\hline 2008 & $\$ 16,808$ & -13.92 & 84.37 & 146,600 & -13.51 & 79.46 \\
\hline 2009 & $\$ 10,615$ & -36.85 & 53.28 & 104,800 & -28.51 & 56.8 \\
\hline 2010 & $\$ 13,817$ & 30.16 & 69.36 & 99,700 & -4.87 & 54.04 \\
\hline 2011 & $\$ 16,041$ & 16.1 & 80.52 & 104,000 & 4.31 & 56.37 \\
\hline 2012 & $\$ 15,519$ & -3.25 & 77.9 & 118,000 & 13.46 & 63.96 \\
\hline 2013 & $\$ 16,463$ & 6.08 & 82.64 & 117,000 & -0.85 & 63.41 \\
\hline 2014 & $\$ 17,023$ & 3.4 & 85.45 & 160,000 & 36.75 & 86.72 \\
\hline 2015 & $\mathrm{Nd}$ & $\mathrm{Nd}$ & $\mathrm{Nd}$ & 173,000 & 8.12 & 96.76 \\
\hline TC 2005-2009+ & -46.71 & & & -43.19 & & \\
\hline TC 2010-2014+ & 23.2 & & & 60.48 & & \\
\hline
\end{tabular}

Fuente: Delphi (2010, 2011 y 2014).

*Base $2005=100$.

+Tasa de crecimiento del periodo.

** No se considera desde 2001 el periodo dada la presencia sólo de datos de empleo de ese año y ausencia entre 2001 y 2005.

Sobresale un elemento en el cuadro 3, el total de centros técnicos, en la sección de totales, a finales de 2013 Delphi reportaba 15 alrededor del mundo. En el caso de Norteamérica se reportaron cinco, pero éstos no se concentran como en el caso de la producción en México, cuatro de ellos se sitúan en Estados Unidos y sólo uno en Ciudad Juárez, Chihuahua, México. Dicho centro, fue fundado en 1995 con 564 ingenieros, hoy en día Delphi reporta tener en México más de 2,000 ingenieros.

El caso de Delphi para México es relevante por varios motivos, entre ellos:

1) traslado de la producción de Estados Unidos al vecino país de la frontera sur;

2) creciente e importante número de empleos en México bajo el programa de la IME; 
3) introducción de Centros de Tecnología (ahora tres en México);

4) creciente número de ingenieros y no sólo obreros;

5) número importante de patentes (en Estados Unidos) de inventores mexicanos que trabajan en Delphi.

Cuadro 3. Locaciones manufactureras de las que es propietaria Delphi

\begin{tabular}{|c|c|c|c|c|c|c|c|}
\hline & Año & $\begin{array}{l}\text { Arquitectura eléctri- } \\
\text { ca y electrónica }\end{array}$ & $\begin{array}{l}\text { Electrónico y } \\
\text { seguridad }\end{array}$ & $\begin{array}{l}\text { Sistema de } \\
\text { propulsión }\end{array}$ & $\begin{array}{l}\text { Sistemas } \\
\text { térmicos* }\end{array}$ & Total & $\begin{array}{l}\text { Centros } \\
\text { técnicos }\end{array}$ \\
\hline \multirow{3}{*}{ Norteamérica } & 2010 & 16 & 3 & 4 & 5 & 28 & 5 \\
\hline & 2013 & 29 & 3 & 4 & 3 & 39 & 5 \\
\hline & 2015 & 30 & 3 & 4 & & 37 & 4 \\
\hline \multirow{3}{*}{$\begin{array}{l}\text { Europa, Este medio } \\
\text { y África }\end{array}$} & 2010 & 15 & 9 & 12 & 4 & 40 & 4 \\
\hline & 2013 & 22 & 9 & 10 & 2 & 43 & 5 \\
\hline & 2015 & 32 & 7 & 10 & & 49 & 5 \\
\hline \multirow{3}{*}{ Asia Pacífico } & 2010 & 9 & 2 & 5 & 4 & 20 & 4 \\
\hline & 2013 & 19 & 3 & 5 & 5 & 32 & 4 \\
\hline & 2015 & 25 & 3 & 5 & & 33 & 4 \\
\hline \multirow{3}{*}{ Sudamérica } & 2010 & 5 & 1 & 2 & 1 & 9 & 1 \\
\hline & 2013 & 8 & 1 & 2 & 1 & 12 & 1 \\
\hline & 2015 & 5 & & 2 & & 7 & 4 \\
\hline \multirow{3}{*}{ Total } & 2010 & 45 & 15 & 23 & 14 & 97 & 14 \\
\hline & 2013 & 78 & 16 & 21 & 11 & 126 & 15 \\
\hline & 2015 & 92 & 13 & 21 & & 126 & 14 \\
\hline
\end{tabular}

*En 2015 las actividades para sistemas térmicos fueron descontinuadas.

Fuente: Elaboración propia con base en Delphi (2010, 2013 y 2015).

Cuadro 4. Características generales Delphi México

\begin{tabular}{|c|c|c|}
\hline Año & Empleados & Plantas* $^{*}$ \\
\hline $2002^{\text {a }}$ & 77,000 & 57 \\
\hline $2005^{\mathrm{b}}$ & 66,000 & 48 \\
\hline $2009^{c}$ & 47,000 & 45 \\
\hline $2013^{\mathrm{d}}$ & 54,000 & 48 \\
\hline
\end{tabular}

*El número no es coincidente con los reportados en los balances que hace la empresa de sus propiedades porque se consideran filiales.

arias (2004)

${ }^{\text {b Carrillo (2007) }}$

c Delphi (2014)

dVillalpando (2009)

Fuente: Elaboración propia con base en datos de Arias (2004), Carrillo (2007) y Delphi (2013). 


\section{I.2. Relevancia académica de Delphi}

Lo expuesto arriba permitió una serie de discusiones conceptuales en torno a la evolución de Delphi, durante los años que lleva instalada México, en ellas se remarca su importancia en el ámbito productivo y. sobre todo, tecnológico. Entre esas discusiones destaca el identificar en esta empresa (y en recientes fechas a otras empresas como Valeo, Lear, Philips, Thomson) la formación de diferentes generaciones de maquila (Carrillo y Hualde, 1997a y 1997b; Carrillo y Lara, 2004; Carri1lo, 2007). Carrillo y Hualde (1997a y 1997b) identificaron tres generaciones de maquila en México, destaca Delphi como empresa que se situaba en una tercera y ahora cuarta generación. Una primera generación de maquilas fue descrita como una maquiladora totalmente intensiva en trabajo manual, una segunda se determina por la racionalización del trabajo y la tercera se describe como una maquila intensiva en conocimientos. A continuación se describe la tercera generación: "las maquiladoras de tercera generación se distinguen por una presencia mayor de corporaciones transnacionales. Ya no se trata de plantas orientadas al ensamble o a la manufactura, sino a la investigación y desarrollo y al diseño (IDD)" (Carrillo, 1997: 752). Actualmente se identifica a una nueva generación de maquila en México, considerando que la base de la empresa ya no es el conocimiento sino la logística y las tecnologías de la información que hacen posible la coordinación entre intra e inter firma, en los ámbitos de venta, producción y desarrollo (Carrillo y Lara: 2004) $)^{4}$.

Además de las anteriores posturas, a Delphi también se la ha planteado como una empresa que ha generado capacidades tecnológicas (Arias, 2004; Arias y Dutrenit, 2003), a través del Centro Técnico instalado desde 1995 en Ciudad Juárez, México. Y, por otro lado, se ha mencionado que Delphi ha impulsado ventajas competitivas para la región de Chihuahua, México (Ramírez y Correa, 2002).

Aunado a lo anterior, se destaca que Delphi cuenta con el registro de 160 patentes hasta 2016 (en Estados Unidos) a nombre de inventores mexicanos, esto sin duda es relevante dada la nula actividad de patentamiento de agentes mexicanos

${ }^{4}$ La anterior, ha sido sujeto de debates, De la Garza (2013) ha criticado esto: el definir una tercera generación sólo por conocimiento, al señalar que se ha olvidado el carácter productivo y centrarse en uno simbólico (conocimientos per se), además señala la falta de argumentos para plantear las causas del paso de una generación a la otra. Por su parte, Juárez (2010) ha hecho notar que el aprendizaje a partir de Delphi para México es inexistente, y que la ventaja competitiva que pudiera obtener se encuentra sustentada en bajos costos salariales (aún con mano de obra altamente calificada), respecto al país vecino del norte. Esto intenta contradecir la idea de que la nueva ventaja competitiva de Delphi se centra en el conocimiento tecnológico. 
(empresas e inventores). Esto puede remarcar el caso de Delphi como un modelo en el contexto industrial mexicano. Es indiscutible que Delphi, mediante inversión extranjera directa ha generado empleos en México, directos e indirectos mediante la proveeduría. Pero como se mencionó en la primera parte de este apartado esto obedece sustancialmente a una reestructuración de la empresa ${ }^{5}$, cuya estrategia sugería mover la producción de sus plantas norteamericanas al vecino país del sur, que cuenta con programas para la maquila de exportación, y existe un sustancial subsidio a las importaciones, además, de mano de obra considerablemente más barata, hasta 20 veces menor que en Estados Unidos (Juárez, 2010). A esto se suma la problemática de General Motors, primero subsidiaria y después principal comprador de la producción de Delphi.

Por otro lado, la discusión acerca de los efectos positivos o nulos del Centro Técnico hacia empresas mexicanas no está cerrada. En el presente trabajo, se parte de que si bien existe una sustancial ocupación de recursos humanos altamente capacitados (no sólo en el Centro Técnico sino también en las plantas) y se desarrollan tecnologías al interior de estos centros, se podrían encontrar fuertes limitaciones para obtener spillovers tecnológicos a partir de la estrategia de Delphi y la fuerte competencia por acceder a dichos spillovers.

En este sentido el presente trabajo abunda en la búsqueda de una temática que analice la presencia/ausencia de spillovers mediante dos conceptos adicionales a éstos: exploración y explotación. Así mismo, se considera que es necesaria la incorporación de la estrategia internacional de la empresa (parte de ella ya recopilada líneas arriba y que está ausente en las investigaciones citadas previamente), principalmente porque es evidente (por lo ya expuesto) que la presencia en México no se puede ver como un hecho aislado e independiente de la posición de Delphi en el mundo. En ese sentido, en el siguiente apartado se exponen conceptos más amplios que permitan sintetizar la estrategia de la empresa Delphi y el lugar que ocupa México.

\section{SPILLOVERS, EXPLORACIÓN Y EXPLOTACIÓN DE CONOCIMIENTOS}

Los spillovers se pueden definir como los efectos (positivos o negativos) que impactan a un tercero, el cual no participa de forma directa en la producción de esos efectos, que pueden favorecer o empeorar la situación del que los produce. En ese

${ }^{5}$ Cabe mencionar que además de lo citado, existe una tendencia a la relocalización de las plantas automotrices, esto ha sido analizado a profundidad por Covarrubias (2014), en el caso de la industria automotriz mexicana. 
sentido, los spillovers son externalidades (Laffont, 1993), efectos indirectos de una actividad de consumo o producción sobre una función de utilidad. Dichas externalidades pueden provocar de forma indirecta tanto efectos positivos (como beneficios y transferencia de conocimientos a un tercero sin que el que los provocó obtenga algo a cambio) como negativos (imponer costos a un tercero sin una compensación). En este sentido, se pueden encontrar externalidades de diferentes ámbitos como tecnológicas, productivas y pecuniarias (Blomström y Kokko, 1998; Kokko, 1994; Scitovsky, 1954).

El primer referente al concepto de spillovers de conocimiento lo hace Marshall (1890), al hablar de la aglomeración de las actividades económicas y sus efectos, como: acceso a mano de obra calificada, acceso a proveedores especializados y spillovers de conocimiento entre empresas. Sin embargo, no se profundiza en dicho concepto hasta los planteamientos de Pigou (1920), quien remarcó que los spillovers son la fuente de la diferencia entre el producto privado y el producto social.

Los spillovers tecnológicos o de conocimientos se gestan básicamente porque el conocimiento se presenta como un bien público, el cual tiene la característica de ser no rival y no excluible, esto permite (a diferencia de un bien privado) que pueda ser usado por más de un agente (empresa), ya sea para imitarlo o para la generación de nuevos conocimientos tecnológicos (Montobbio y Sterzi, 2011) ${ }^{6}$.

Los spillovers de conocimientos en un país podrían gestarse por el comercio de mercancías (Coe y Helpman, 1995; Bernard y Jensen, 1999), la movilidad laboral (Pesola, 2007), la inversión extranjera directa (Blomström y Kokko, 1998) y la vigilancia tecnológica. Sin embargo, a nivel de empresa, la generación de spillovers podría depender de dos elementos: 1) de la capacidad que tengan los receptores de los spillovers, capacidad para poder asimilar (e innovar sobre) los conocimientos tecnológicos, en resumen, de las capacidades de absorción (Cohen y Levinthal, 1990); 2) de la estrategia de generación de conocimientos que desarrolle la empresa para su propio beneficio o para evitar que otros se vean beneficiados del conocimiento generado, tratando de reducir los efectos de la imperfecta apropiabilidad de las innovaciones (Griliches, 1998). Es en este último punto en el que se ahondará, retomando dos conceptos centrales para el funcionamiento y sobrevivencia de una empresa en un entorno de alta competencia y con base tecnológica: exploración y explotación (Levinthal y March; 1993) de conocimientos.

${ }^{6}$ Los spillovers de conocimientos provoca en principio ineficiencias en el sentido de Pareto (por ser una externalidad), pero también múltiples equilibrios (Arthur, 1994) causado por los rendimientos crecientes a escala. 
Dada la búsqueda de economías de escala, la empresa tiende a la especialización de algunos productos, esto exige rutinas y provoca que la empresa tenga una visión miope, ya que no ve más allá de su vecindad, ni nuevos productos que puedan requerir sus clientes (Levinthal y March, 1993: 101), se tiende a la explotación. La empresa también enfrenta cambios en las necesidades de sus consumidores y competencia de otras empresas, por lo que esa especialización podría llevar a sus productos a una depreciación. Por otro lado, los nuevos productos o desarrollos tecnológicos, siempre son riesgosos, sin embargo, la exploración de nuevos productos le permite acceder a nichos de mercado futuros. En ambos casos siempre existen innovaciones, ya sean radicales o sólo incrementales (de procesos o de productos). En este sentido, la innovación se puede comprender como un proceso en el que se combina la explotación y la exploración (Nooteboom, 2000 y 2009) $)^{7}$.

La exploración es una estrategia de largo alcance que impulsa la novedad a partir de nuevos descubrimientos, en un contexto en donde existe incertidumbre y se aprende a través del ensayo y el error. Mientras que la explotación es de corto plazo, implica lograr la eficiencia manteniendo los estándares y las rutinas dominantes (García y Reyes 2015). Por lo expuesto, la empresa podría resolver dicho trade-off por medio de dos alternativas: una estrategia de equilibro puntuado y de empresa ambidiestra.

March (1991) y Levinthal (1993) señalan que una empresa busca en principio la novedad para hacerse de uno o varios nichos y luego explotar los que resulten más beneficiosos. El inicio sería un proceso de exploración de diseños (en productos, rutinas y organizaciones) al cual le seguiría uno de explotación o de selección de aquellos productos y procesos que le resulten más beneficiosos, en este sentido el proceso de exploración (dados los recursos invertidos en la búsqueda) tendría que ser mucho más corto que el de explotación. Esto mostraría un proceso primero de diversidad de diseños, después un declive de ésta, y luego la diversidad permanecería constante por un largo periodo (Page, 2011; Reyes, 2016). A este proceso se le denominó equilibrio puntuado por Anderson y Tushman (1990). ${ }^{8}$ Por

${ }^{7}$ La transición de los procesos de explotación a los de exploración está mediada por procesos creativos que toman la forma de nuevos productos o procesos innovadores. Esta espiral de descubrimiento abarca múltiples actividades, tales como: "invención/generación de idea, desarrollo, comercialización, penetración de mercado, difusión, consolidación, y diferenciación, lo cual conduce al comienzo de una invención. Esto debería explicar cómo la explotación y la exploración se suceden y emergen una de la otra" (Nooteboom y Stam, 2008: 8).

${ }^{8}$ Anderson y Tushman (1990), March (1991) y Levinthal (1993), utilizan el concepto de exploración/explotación y el de equilibrio puntuado para describir la evolución a nivel de sectores tecnológicos, la explicación que apuntan los autores se divide en dos partes: primero surge un 
otro lado, He y Wong (2004) plantean que la empresa puede afrontar el trade-off mediante un equilibro entre la búsqueda de nuevos nichos (por ejemplo lanzando nuevos productos) y explotando los existentes en un mercado maduro o en el que tiene experiencia. Esta forma de búsqueda equilibra el trade-off en la empresa, siendo una combinación de exploración y explotación, a las empresas que desarrollan la capacidad se les suele denominar empresa ambidiestra.

La relación entre la exploración, explotación y spillovers ahora se hace explícita, la explotación es un intento por hacer frente a la imperfecta apropiabilidad de las innovaciones, o la generación de spillovers para la competencia, por otro lado, la exploración es la toma de spillovers (esquema 1).

Esquema 1. Exploración, explotación y estrategias combinadas ante la amenaza de exploración y explotación de otra empresa

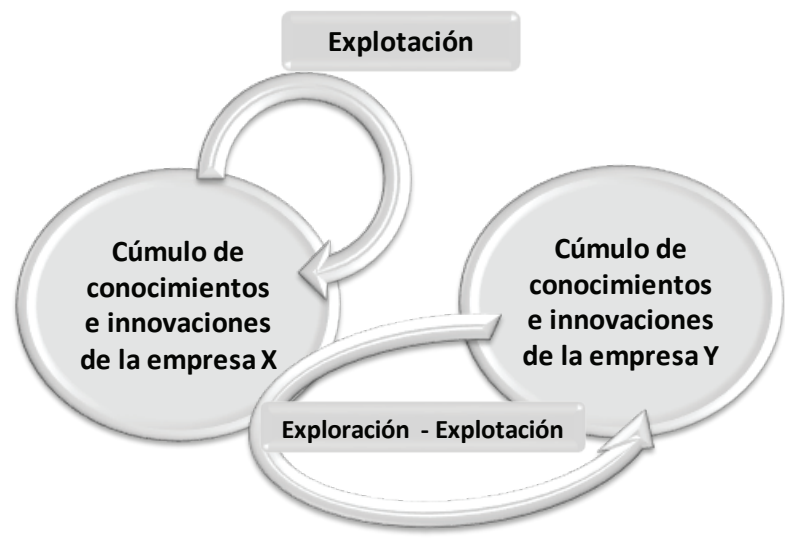

Fuente: Elaboración propia.

En términos de la localización de la empresa se busca maximizar la explotación de las relaciones cercanas (proveeduría, recursos, conocimientos), aprovechar los conocimientos de la competencia y minimizar los spillovers de la misma (Alcácer y Chung, 2007). En este tenor las empresas transnacionales (ET) no están exentas

proceso de exploración de varias tecnologías en un mismo sector, seguido de la explotación de las tecnologías más aptas en el mercado. Este proceso de exploración/explotación puede ser representado por un el equilibrio puntuado, donde los incrementos de diversidad son traducidos en exploración de tecnologías y un decremento en explotación. La teoría del equilibrio puntuado señala que le evolución de las especies no fue siempre gradual, sino que señala que después de cada extinción se presentó un proceso de alta diversidad de especies para después un declive de la diversidad (Eldredge y Gould, 1972 y 1977). 
de dicha búsqueda. Por ejemplo, la investigación de Kuemerle (1997), señala que existen dos motivos para la relocalización de actividades de $\mathrm{I}+\mathrm{D}$ (como el caso de los Centros Técnicos de Delphi): a) las ET pueden absorber nuevo conocimiento de países extranjeros; $b$ ) recortar los tiempos entre las etapas de desarrollo del producto y su llegada al mercado dada la cercanía de esas actividades. Esto sirve para aumentar la capacidad de sede de la ET, además de explotar las capacidades de la transnacional.

En esa misma línea, Cantwell y Piscitello (2003) subrayan que las ET sitúan sus actividades en el extranjero para capturar spillovers de conocimiento e identificaron al menos tres tipos de spillovers: interindustria, intraindustria y basados en ciencia. Algunos de estos estudios (Alcácer y Chung, 2007; Alcácer y Zhao, 2010) han considerado la competencia como el factor decisivo, ante una alta competencia las ET buscarán aprovechar de forma más eficiente y con mayor velocidad el conocimiento generado en los centros $\mathrm{I}+\mathrm{D}$ que regularmente podrían situarse en clúster industriales donde existe competencia, lo que reduciría el flujo de conocimientos hacia la competencia (Alcácer y Zhao, 2010) y ayudará a no ser presa de la depreciación tecnológica. Se busca minimizar spillovers que favorezcan al competidor (Alcácer y Chung, 2007).

Ante este escenario y trasladando los conceptos enunciados en párrafos arriba al caso de la empresa Delphi, se debe reflexionar sobre si realmente las empresas nacionales alcanzan a tomar spillovers tecnológicos y si Delphi realmente lo plantea como una estrategia propia y además considerando los agentes mexicanos en ésta, o si algún agente externo está aprovechando los conocimientos e innovaciones generados por Delphi. En este sentido, en el siguiente apartado se presenta la metodología de los indicadores e insumos a utilizar para operacionalizar los conceptos de este apartado.

\section{LAS PATENTES COMO INSUMO E INDICADOR}

El estudio está basado metodológicamente en operacionalizar los conceptos del apartado 2 mediante el uso de patentes para responder a las preguntas de investigación. Por lo que a continuación se expone el uso específico de las patentes en este estudio y su justificación.

La patente es definida en el Manual de Oslo (OCDE y eURostat, 2005, 30) como "un derecho de propiedad legal sobre una invención, el cual es otorgado por una oficina nacional de patentes. Una patente otorga a sus propietarios un monopolio (con duración limitada) para explotar la invención patentada lo cual intenta permitir un amplio uso social del descubrimiento". Por lo anterior, una patente es un documento jurídico, legal y técnico, porque describe a detalle una invención de un 
artefacto o de un proceso y delimita su alcance. Una vez descrita la invención, se puede reclamar el derecho a ser dueño de la invención en un espacio geográfico y temporal determinado, dado el marco jurídico que establezca el gobierno del país que la otorgue.

Las patentes son el resultado de un proceso de búsqueda de agentes diversos como inventores, empresas, universidades, y otras organizaciones para la solución de problemas mediante la invención de nuevos procesos y productos, que permitan la obtención de un beneficio en el mediano plazo. Las patentes son entonces una aproximación de la actividad inventiva y de la innovación de diferentes agentes.

En ese sentido, las patentes muchas veces han servido para cuantificar el desempeño tecnológico de los países, sectores, organizaciones. Así como, la correlación del esfuerzo inventivo con otras variables económicas y tecnológicas. Al respecto ha existido una larga cadena de investigaciones como propuesta de nuevos indicadores y tipos de análisis (Schmookler, 1954; Comanor y Sherer, 1969; Pavitt, 1984; Jaffe, 1986; Griliches, 1990; Jaffe, Trajtenberg y Henderson, 1993; Jaffe y Trajtenberg, 1998; Hall, Jaffe y Trajtenberg, 2001; Fleming y Lee, 2001; Hu y Jaffe, 2003; Sorensen, Fleming y Rivkin, 2006; Fleming, King y Juda, 2007). En ese sentido la patente puede fungir como un indicador del esfuerzo inventivo.

Las patentes también son fuente de información técnica y bibliográfica, información de quien (inventor, empresa) la patenta, en qué sector tecnológico se hace, en qué año, de dónde proviene el conocimiento tecnológico inserto en una patente, y quién utiliza dicho conocimiento para la producción de más patentes (Jaffe y Trajtenberg, 1998). Una vez considerado que las patentes son más que un derecho de propiedad, este trabajo considera que representan un proxy de la actividad inventiva y una fuente de información valiosa. Además se plantea que mediante las citas contenidas en ellas pueden representarse los flujos de conocimiento, entre inventores, empresas, regiones, países e industrias (Jaffe, Trajtenberg y Henderson, 1993; Jaffe y Trajtenberg, 1998; Hall, Jaffe y Trajtenberg, 2001; Hu y Jaffe, 2003), y delimitando su origen y dirección pueden representar spillovers de conocimiento. Griliches (1979) fue el primero en desarrollar un modelo que representara la función de producción de conocimiento (Cobb-Douglas), haciendo uso de patentes, a partir de ahí se reconoce la importancia del cálculo de dicha función para el cálculo de la difusión de conocimiento. Por otro lado, el análisis de los spillovers con patentes continúa principalmente con las aportaciones de Jaffe (1984; 1986), el cual estableció la relación entre la demanda, spillovers tecnológicos y el crecimiento de la productividad (como un efecto de los spillovers).

Un salto importante de la investigación de los spillovers se da con la incorporación de las citas de patentes. La investigación no sólo se centraba en determinar la relación entre patentes, gasto en $\mathrm{I}+\mathrm{D}$ e incremento de productividad 
(spillovers), sino además ahora se podría determinar la dirección de los spillovers (parte de esto se basó en el desarrollo de las tecnologías de la información y la digitalización de patentes para el caso de USPTO, lo que permitió utilizar toda la información contenida en una patente). A continuación se dio un incremento sustancial en los estudios sobre flujos de conocimiento, ya sea para determinar su relación con la concentración geográfica (Jaffe, Trajtenberg y Henderson, 1993), conocer el flujo de conocimiento entre países (Jaffe y Trajtenberg, 1998; Hu y Jaffe, 2003), etcétera9. Estudios posteriores sentaron las bases para el análisis tanto a nivel de regiones como de empresas, por ejemplo, Branstetter (2006) usa una función de patente para estimar los spillovers a nivel de empresa en Japón. Otros como Bottazzi y Peri (2007), encuentran que las ideas generadas a nivel internacional afectan la innovación de los países, dado el efecto spillovers. Además de esto, se ha considerado la coautoría en las patentes como otra forma de medir los spillovers como en el caso de Montobbio y Sterzi (2011).

En lo que respecta a estudios de esta índole en América Latina o México, son escuetos, principalmente por la información poco estructurada en los países latinoamericanos y el número reducido de patentes registradas en dichos países. Sin embargo, destaca el estudio de Montobbio (2007), en el cual se encontró que el conocimiento producido en Estados Unidos ha impactado (vía spillovers) en la región.

Por último, cabe subrayar que las citas de patentes no sólo representan un flujo de conocimiento o un spillover, también pueden influir en que éstos ocurran, de hecho, la publicación de una patente tiene como objetivo la difusión de las innovaciones, ergo, la patente per se promueve los spillovers. En ese sentido, la patente no sólo representa parte de la actividad inventiva de diferentes agentes, sus citas pueden reflejar parte de las externalidades (Goel, 1995).

\section{III.1. Las patentes representando la explotación y la exploración}

Las patentes contienen citas, estas son referencias a artículos, libros y en mayor medida a otras patentes, en ellas se reconoce de dónde proviene el conocimiento de una patente y cuál es la fuente de conocimiento tecnológico de una invención. A su vez una patente una vez emitida es susceptible de ser citada. El acto de citar regularmente se denomina backward y el de ser citado forward (Jaffe, Trajtenberg y Henderson, 1993).

${ }^{9}$ Es pertinente mencionar que las citas también se han ocupado entre otras cosas para medir la relevancia o el valor de una patente (Albert et al., 1991) o para obtener indicadores basados en sistemas complejos (Sorensen, Rivkin y Fleeming, 2002). 
El esquema 2 representa una serie de patentes y sus citas (flechas). La patente 3 en el centro del esquema cita a la patente 1 y 2 de los agentes A y D, esto se denominaría backward, estos agentes pueden representar un inventor, una empresa, un laboratorio, una universidad, etcétera. ${ }^{10}$ Por otro lado, la patente 3 puede recibir citas de otras patentes como 4, 5 y 6 . La cita que recibe de las patentes 4 y 6 de los agentes A y E podrían describirse como spillovers de conocimientos tecnológicos. En el caso de la patente 5 es una patente del agente $\mathrm{C}$, a esto se denomina regularmente auto-cita, porque un agente cita a patentes de él mismo. La auto-cita, se puede reconocer como explotación del conocimiento ${ }^{11}$ según lo expuesto líneas arriba. De esta forma se puede reconocer el esquema de explotación, y plantear, además, de quién y en qué grado está haciendo uso (spillovers) de los conocimientos tecnológicos plasmados en una patente (Jaffe, 1986; Jaffe, Trajtenberg y Henderson, 1993; Jaffe y Trajtenberg, 1998). En caso concreto de Delphi, se deberá determinar si es la misma empresa la que aprovecha en mayor medida sus conocimientos o si son sus competidores. Dada la afluencia de inversión en México habrá que reconocer si existe la presencia de spillovers tecnológicos de agentes mexicanos: empresas e inventores.

Para profundizar, se consideraron las patentes de Delphi. Se tomaron en cuenta 5,112 patentes otorgadas en la Oficina de Marcas y Patentes de Estados Unidos (USPTO por sus siglas en inglés) dentro del periodo 1995 a 2014 ${ }^{12}$. Además, se consideraron las citas (51,958 citas) que realizaron dichas patentes (backward) y las citas (34,632 citas) que recibieron (forward). Del backward se considerará determinar el lugar del que retoma los conocimientos Delphi, y si es que existe un proceso de autoreferencia o autocitación. Del forward de las patentes se considerará comprobar si es la misma empresa Delphi o la competencia quien está aprovechando dichos conocimientos tecnológicos y si existen spillovers de conocimientos tecnológicos a agentes mexicanos (cuadro 5).

${ }^{10}$ Una patente siempre contiene la información de quién realiza la invención, esto significa información del inventor. Además aparece el nombre de quién financió a dicha patente que puede ser una empresa, universidad, departamento de gobierno, etcétera. Sin embargo, algunas veces este nombre no aparece porque podría ser que el inventor no recibió financiamiento de un tercero, esto no descarta que un inventor podría ser el dueño de una empresa o hacer el registro por su propia cuenta.

${ }^{11}$ En la autocita y los spillovers se pueden dar también en el backward, el esquema sólo es para ejemplificar.

${ }^{12}$ La empresa Delphi plantea que cuenta con alrededor de 8,000 patentes en su corporativo, desafortunadamente no se cuenta con los números de patente y a qué oficina corresponden dichas patentes. Las empresas de tal magnitud como el caso de Delphi, suelen comprar (y vender) patentes de terceros así como en países diferentes, por lo que la investigación corresponde a patentes de USPTO. Cabe hacer mención que existen sólo cuatro patentes de Delphi en las oficinas del Instituto Mexicano de Propiedad Industrial. 


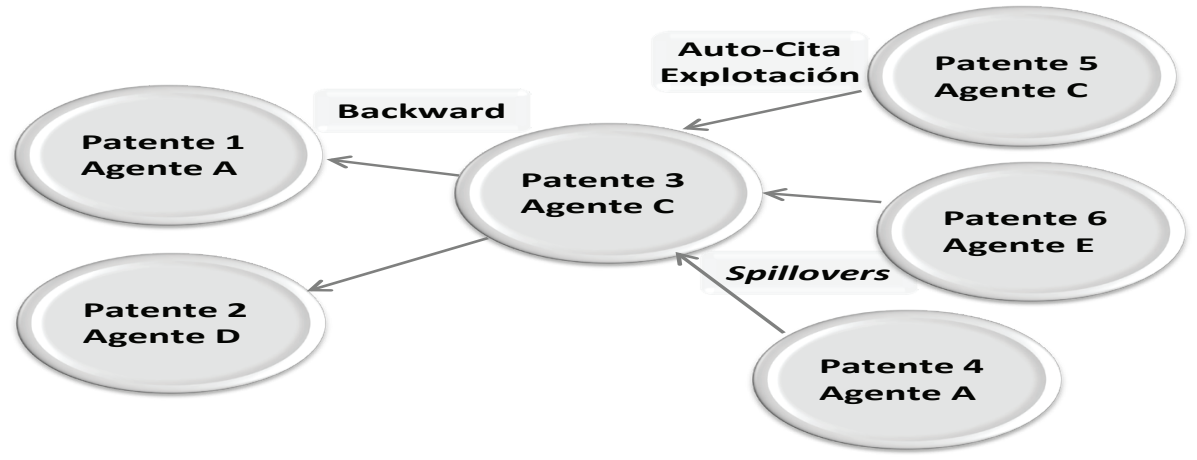

Fuente: Elaboración propia.

Cuadro 5. Estructura de uso de las patentes y sus citas

\begin{tabular}{|l|l|}
\hline Patente & Conceptos \\
\hline \multirow{3}{*}{ Backward } & Estrategia \\
\cline { 2 - 2 } & Explotación: autocitas \\
\cline { 2 - 2 } & Exploración: citas a otros. \\
\hline \multirow{3}{*}{ Forward } & Aprovechamiento de conocimientos: autocitas \\
\cline { 2 - 2 } & Spillovers: citas de otros. \\
\hline
\end{tabular}

Fuente: Elaboración propia.

Después, se detectaron los inventores con residencia mexicana ${ }^{13}$ que han patentado con la empresa Delphi y se indagó si su participación en la empresa ha sido con inventores con residencia en otros países, ${ }^{14}$ cuál ha sido el aprovechamiento que han tenido sus patentes y si los inventores mexicanos han patentado fuera de Delphi, en qué empresas ha sido. Por último, mencionar algunas ventajas y

${ }^{13}$ La residencia del inventor no necesariamente corresponde con su nacionalidad. Un inventor podría tener residencia en Texas, pero ser de nacionalidad mexicana. Centrarse en la residencia obedece a dos motivos: 1) la disponibilidad de información de sólo residencia, datos que ofrece una patente; 2) la residencia podría incorporar de mejor forma las capacidades que se localiza en un país en específico

${ }^{14}$ Una patente puede ser el resultado de uno o más inventores, ingenieros, técnicos, etcétera, además que un inventor puede estar en una o en más patentes. En este caso, un ingeniero de Delphi podría tener más de una patente. 
desventajas del uso de patentes como indicadores tecnológicos y como flujos de conocimiento (Meyer, 2002; Jaffe, Trajtenberg y Fogarty, 2000; Geisler, 2000):

Ventajas: las bases de patentes se consideran como bases sistematizadas a lo largo de los años, ya que existe una serie de tiempo larga, (principalmente la base de patentes estadounidense); los datos acerca de las patentes son fáciles (relativamente) de manejar como nacionalidad, empresa propietaria, año, citas; podrían ser relacionados con otro tipo de medidas, por ejemplo, nivel comercial, tecnológico, gasto en investigación y desarrollo; las patentes contienen información útil y reveladora del origen de la invención, debido a su estructura de un documento legal; las patentes de una oficina de patentes, muestra información clasificada homogéneamente acerca de las industrias y origen geográfico de las invenciones; las patentes son consideradas como indicador de nivel tecnológico.

Desventajas: las patentes no siempre alcanzan una aplicación de producción y por lo tanto de comercialización, representan sólo una parte de la actividad inventiva de las empresas y en general de la economía; existe gran parte de conocimientos que no se pueden codificar, y mucho menos conocimientos que son llevados a una patente y que permanecen en una estructura tácita; los datos de las patentes no representan el valor comercial contenido en ellas; el conocimiento de una patente puede nunca llegar a tener relevancia comercial; las patentes son invenciones no innovaciones; las patentes sólo capturan los spillovers que ocurren entre invenciones patentadas, lo cual subestima el número de posibles spillovers (Scherngell y Jansenberger, 2006), otros canales de transferencia de conocimientos pueden ser omitidos como la habilidad y movilidad laboral, la compra de tecnología (que fueron citadas párrafos anteriores); algunas citas pueden no representar flujos de conocimiento ni spillovers, por ejemplo algunos dictaminadores de patentes sugieren/agregan citas a la patente (Scherngell y Jansenberger, 2006).

\section{DELPHI SU EXPLORACIÓN, EXPLOTACIÓN Y SPILLOVERS}

En la oficina de patentes de Estados Unidos Delphi tiene registradas alrededor de 5,236 patentes entre 1995 y 2015. En la gráfica 1 se muestra su crecimiento, se identifican al menos cuatro periodos: 1) 1995-1999, se muestra un reducido registro de patentes, pasando de una patente a 10 por año ${ }^{15}$; 2) 2000-2003, crecimiento acelerado en patentes registradas (1,920 patentes); 3) 2004-2009, se presenta una

${ }^{15}$ Esto será significativo cuando se considere la cantidad total de citas hechas o recibidas, dado el número reducido de patentes otorgadas, ya que un pequeño incremento podría tener un cambio sustancial en el momento de observar alguna tendencia. 
caída que se detiene en 2009 (aunque el número de patentes es considerable: 2,363) y; 4) 2010-2014, sigue una tendencia decreciente en el número de patentes por año (804 patentes en los últimos cinco años). Considerando estos cuatro periodos a continuación se presenta la información de backward (citas hechas) y forward (citas recibidas) del total de patentes de Delphi ${ }^{16}$.

Gráfica 1. Patentes otorgadas a Delphi en USPTO, 1995-2014

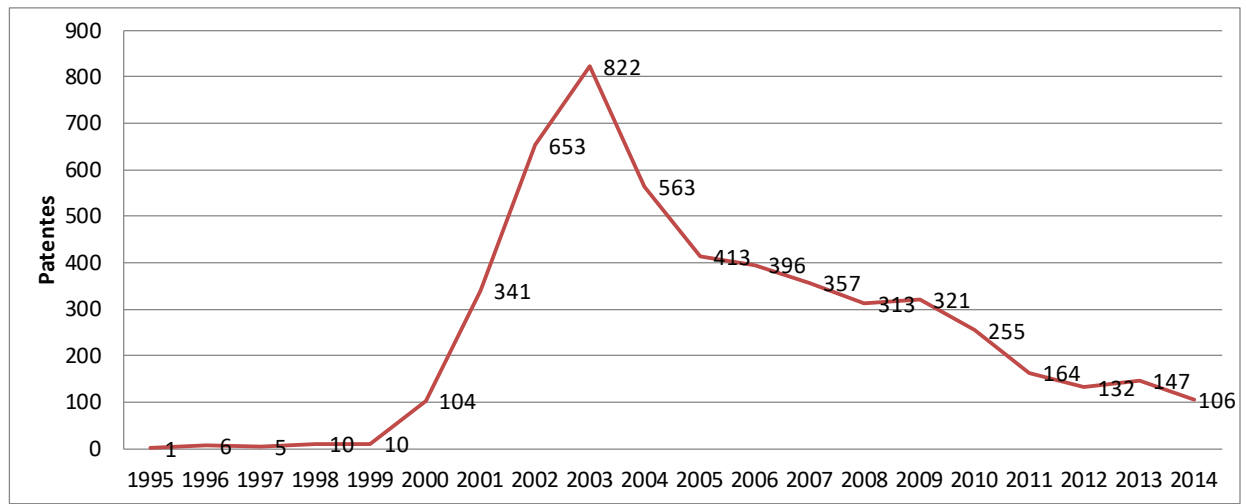

Fuente: Elaboración propia con base en datos de uspto.

\section{IV.1. Análisis backward en Delphi}

Con el fin de conocer la principal fuente del conocimiento tecnológico de Delphi, sobre qué conocimientos ha indagado, explorado y explotado, se retoman las patentes de dicha empresa y se presentan los resultados en el Cuadro 6 y la Gráfica 2. El cuadro presenta por periodo, qué agentes (empresas, universidades, centros de investigación, etcétera) son los 10 más citados (backard) por Delphi.

En el primer periodo la empresa que aparece más citada es General Motors (GMC) con 16 por ciento de citas (29), luego la empresa Yazaki con 8.7 por ciento (15 citas), después, empresas con menos de 4 por ciento de las citas recibidas cada una de ellas. En el segundo periodo (2000-2003), sigue siendo GMC la más citada con 11.1 por ciento de las citas, y aparece Delphi en segundo lugar con 3.4 por ciento, después otras compañías con menos de 3 por ciento de las citas como Ford,

${ }^{16}$ El objetivo de no incluir datos de 2015 es para homologar las citas backward y forward ya que patentes muy recientes no podrían recibir citas. Se subraya que el número de patentes en USPTO para 2015 para Delphi fue de 117. 
R. Bosh, TRW Honda, etcétera. Para el tercer periodo (2004-2009), las auto-citas ya representan 20.11 por ciento de las citas, y las citas a GMC son las siguientes en importancia. Para el último periodo, las auto-citas se reducen a 14 por ciento.

Cuadro 6. Citas de patentes de Delphi hechas a principales empresas

(backward de 10 principales empresas)

\begin{tabular}{|c|c|c|c|c|c|}
\hline \multicolumn{3}{|c|}{ 1995-1999 } & \multicolumn{3}{|c|}{$2000-2003$} \\
\hline Empresa & Citas & $\%$ & Empresa & Citas & $\%$ \\
\hline Total citas hechas & 172 & 100 & Total citas hechas & 16159 & 100 \\
\hline GMC & 29 & 16.9 & GMC & 1792 & 11.1 \\
\hline Yazaki & 15 & 8.7 & Delphi & 542 & 3.4 \\
\hline ITT Industries & 6 & 3.5 & Ford & 463 & 2.9 \\
\hline Nissin Kogyo & 6 & 3.5 & R. Bosch & 457 & 2.8 \\
\hline AMP & 5 & 2.9 & TRW & 430 & 2.7 \\
\hline Ford & 5 & 2.9 & Honda & 401 & 2.5 \\
\hline Lucas & 5 & 2.9 & Mitsubishi & 295 & 1.8 \\
\hline Sumitomo & 4 & 2.3 & Nissan & 294 & 1.8 \\
\hline Fichtel \& Sachs & 3 & 1.7 & Toyota & 290 & 1.8 \\
\hline Mazda & 3 & 1.7 & Delco & 253 & 1.6 \\
\hline Resto de citas & 91 & 52.9 & Resto de citas & 10942 & 67.7 \\
\hline $\begin{array}{l}\text { Total empresas cita- } \\
\text { das }\end{array}$ & \multicolumn{2}{|c|}{85} & \multicolumn{3}{|l|}{2177} \\
\hline \multicolumn{3}{|c|}{$2004-2009$} & \multicolumn{3}{|c|}{ 2010-2013 } \\
\hline Empresa & Citas & $\%$ & Empresa & Citas & $\%$ \\
\hline Total citas hechas & 30114 & 100 & Total citas hechas & 5513 & 100 \\
\hline Delphi & 6057 & 20.11 & Delphi & 776 & 14.08 \\
\hline GMC & 1672 & 5.55 & GMC & 161 & 2.92 \\
\hline TRW & 713 & 2.37 & Denso & 129 & 2.34 \\
\hline Ford & 664 & 2.2 & R. Bosch & 120 & 2.18 \\
\hline R. Bosch & 539 & 1.79 & Yazaki & 115 & 2.09 \\
\hline Honda & 528 & 1.75 & Ford & 111 & 2.01 \\
\hline Delco & 487 & 1.62 & Siemens & 102 & 1.85 \\
\hline Toyota & 428 & 1.42 & Sumitomo & 88 & 1.6 \\
\hline Mitsubishi & 423 & 1.4 & Delco & 80 & 1.45 \\
\hline Hitachi & 392 & 1.3 & Mitsubishi & 73 & 1.32 \\
\hline Resto de citas & 18211 & 60.5 & Resto de citas & 3758 & 68.2 \\
\hline \multicolumn{3}{|l|}{3387} & \multicolumn{3}{|l|}{1194} \\
\hline
\end{tabular}

Los periodos de año se establecieron hasta 2013 para homologar el backward y forward, dado que el forward sólo se obtuvo citas a 2014.

Fuente: Elaboración propia con base en datos de uspTo.

Cabe resaltar de lo expuesto, que dentro de al menos las 10 empresas más citadas se retoman conocimientos tecnológicos de clientes y rivales para Delphi. Las 
empresas sombreadas corresponden a empresas que son clientes de Delphi (el caso de Ford, Mazda, Honda, Mitsubishi, etcétera), y las no sombreadas empresas son competencia (por ejemplo Yazaki, TRW, Bosh, Denso). Esto significa que existe una vecindad en el conocimiento tecnológico. También sobresale que el soporte importante para Delphi en la construcción de sus conocimientos es la experiencia acumulativa de la explotación de conocimientos (auto-citas) que se ha ido engrosando.

La gráfica 2 complementa esta idea, muestra tres líneas, la primera línea inferior describe el porcentaje de citas que hacen alusión a patentes a la empresa GMC, la línea de enmedio, que inicia su aparición en el año 2002 representa el porcentaje de citas que representan auto-citas (Delphi cita patentes de ella); por último, la línea superior describe el porcentaje de citas que van dirigidas a otras empresas, laboratorios, universidades, etcétera. Como se aprecia, el porcentaje de citas a GMC era relevante en el primer periodo, con 28.1 por ciento de citas recibidas en 1998, sin embargo, cabe recalcar que en este periodo existe un número reducido de patentes de Delphi. Dicha relevancia se fue reduciendo a medida que el número de patentes producidas por Delphi crecía. En su lugar, la auto-citación explicada como explotación fue creciendo en la misma forma que el número de patentes producidas lo hacía, pero con un rezago. Por ejemplo, en las patentes posteriores a 2003 (años en que más se patentó por Delphi, ver gráfica 1) el porcentaje de auto-citas creció de forma considerable: se obtuvieron los valores más altos en 2005 (ver gráfica 2). Por otro lado, cuando se redujo la producción de patentes, también se redujo el número de auto-citas posteriores en términos porcentuales (ver cuadro 7).

Gráfica 2. Backward 1996-2013

(Porcentajes por ańo)

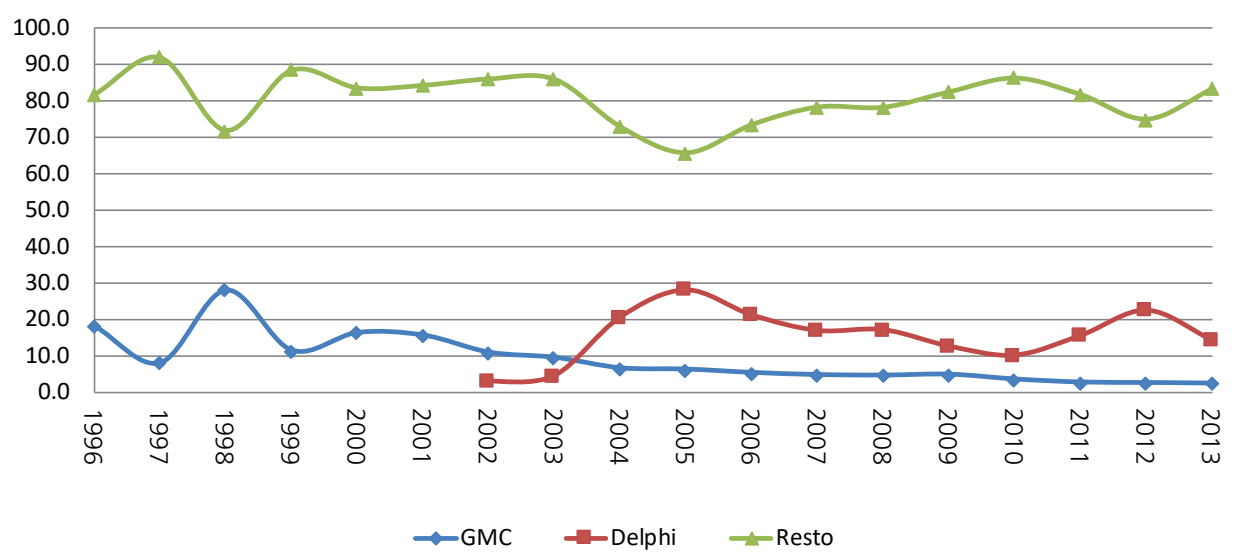

Fuente: Elaboración propia con base en datos de uspTo 2014. 
Esto se explica por tres razones, depreciación, acumulación y competencia. El conocimiento se deprecia en el mercado una vez emitido en la patente, en ese sentido la empresa que lo produce (en este caso Delphi), debe aprovechar explotarlo (auto-cita), ante la competencia que se encuentra en la vecindad tecnológica. La acumulación por su parte habla de que la producción y conocimientos se acumulan y de forma inercial incentiva a producir más, aunque obviamente hay otras fuerzas que pueden detener ese proceso, por ejemplo, los problemas financieros de la empresa. Lo anterior se traduce en capacidad financiera, tecnológica, logística y de vigilancia tecnológica para poder emprender la explotación, este es un proceso interno. Por lo subrayado en apartados anteriores, esto supondría que Delphi es una empresa que combina la exploración y explotación como una empresa ambidiestra.

Cuadro 7. Citas recibidas de empresas (forward 10 principales empresas)

\begin{tabular}{|c|c|c|c|c|c|}
\hline \multicolumn{3}{|l|}{ 1995-1999 } & \multicolumn{3}{|l|}{$2000-2003$} \\
\hline Empresa & Citas & $\%$ & Empresa & Citas & $\%$ \\
\hline Total & 469 & 100 & Total & 21044 & 100 \\
\hline Delphi & 51 & 10.9 & Delphi & 6711 & 31.9 \\
\hline Donnelly Corp. & 36 & 7.7 & GMC & 917 & 4.4 \\
\hline Yazaki & 25 & 5.3 & Ford & 624 & 3 \\
\hline Lear & 24 & 5.1 & R. Bosch & 373 & 1.8 \\
\hline Sumitomo & 18 & 3.8 & Honda & 325 & 1.5 \\
\hline Ford & 17 & 3.6 & Denso & 317 & 1.5 \\
\hline Robert Bosch & 16 & 3.4 & Autoliv & 285 & 1.4 \\
\hline $\mathrm{FCl}$ & 9 & 1.9 & Visteon & 269 & 1.3 \\
\hline Daimler & 7 & 1.5 & Siemens & 246 & 1.2 \\
\hline GMC & 7 & 1.5 & TRW & 236 & 1.1 \\
\hline Resto & 259 & 55.22 & Resto & 10741 & 51.04 \\
\hline \multicolumn{3}{|l|}{ 2004-2009 } & \multicolumn{3}{|l|}{ 2010-2013 } \\
\hline Empresa & Citas & $\%$ & Empresa & Citas & $\%$ \\
\hline Total & 9192 & 100 & Total & 280 & 100 \\
\hline Delphi & 1101 & 12 & Delphi & 23 & 8.2 \\
\hline Donnelly Corp. & 357 & 3.9 & GMC & 17 & 6.1 \\
\hline Ford & 357 & 3.9 & Toyota & 13 & 4.6 \\
\hline GMC & 359 & 3.9 & Ford & 10 & 3.6 \\
\hline Robert Bosch & 175 & 1.9 & Sumitomo & 7 & 2.5 \\
\hline Autoliv & 160 & 1.7 & Continental & 7 & 2.5 \\
\hline Toyota & 154 & 1.7 & Autoliv & 7 & 2.5 \\
\hline Denso & 152 & 1.7 & Robert Bosch & 6 & 2.1 \\
\hline Honeywell & 149 & 1.6 & Hendrickson & 6 & 2.1 \\
\hline Honda & 136 & 1.5 & General Electric & 6 & 2.1 \\
\hline Resto & 6092 & 66.28 & Resto & 178 & 63.57 \\
\hline
\end{tabular}

Fuente: Elaboración propia con base en datos de usPTO. 
Lee (2013) estudió las auto-citas de empresas norteamericanas cuyo promedio era de 12 por ciento (en contra de lo que sucedía con las coreanas con sólo 2 por ciento). Además, que el potencial de auto-citación se eleva con la acumulación de conocimientos. En ese sentido, Delphi, ha podido capitalizar y desarrollar la explotación (aunque en recientes años ha reducido su actividad inventiva). Como se observó en la gráfica 2, la mayoría de los años a partir de 2002, la auto-citación estuvo por encima del 12 por ciento del estudio de Lee.

\section{IV.2. Análisis forward Delphi, aprovechar los conocimientos producidos por Delphi}

En el cuadro 7 se exponen las citas recibidas de las patentes de Delphi correspondientes a cada periodo. Las patentes del primer periodo (1995-1999) han sido ${ }^{17}$ citadas en 10 por ciento por la misma empresa (las patentes han sido citadas 469 veces), esto significa que han sido aprovechadas en 10 por ciento. Donnelly Corp es la empresa que más ha citado a patentes de Delphi ( 7.7 por ciento).

Para el segundo periodo (2000-2003), la auto-citación se incrementa y llega a 31.9 por ciento, le sigue GMC (4.4 por ciento) y Ford (3.0), R. Bosh (1.8 por ciento), Honda (1.5 por ciento), etcétera. La estructura es muy parecida para los siguientes años. Se resalta que quienes aprovechan los conocimientos tecnológicos (después de la misma Delphi) son los clientes principales: GMC, Ford, y Toyota (se resalta la ausencia de vw en éstos, tal vez por el mercado al que está dirigida la producción de Delphi y su producción).

La gráfica 3 expone la evolución del forward de las patentes de Delphi, en términos porcentuales por año, cabe resaltar que a medida que crece y decrece el número de patentes de Delphi las auto-citas hacen lo mismo. Esto podría significar que a medida de que se han reducido el número de patentes, también se ha reducido la capacidad de sostenerse. Esto no quiere decir que los spillovers se incrementan a medida que ha decrecido la producción de patentes.

Por último, después de haber revisado quiénes aprovechan y captan los spillovers tecnológicos, cabe decir que no se encontraron empresas mexicanas dentro de estos spillovers. No existen derramas tecnológicas que sean aprovechadas al interior del país.

${ }^{17}$ Cabe señalar que las patentes que el forward de una patente puede seguir creciendo debido a que una patente siempre es susceptible de ser citada. Por ejemplo, las patentes de 1995 pueden hoy en 2014 seguir siendo citadas. 
Gráfica 3. Forward de Delphi, 2000-2011

(Porcentajes por ańo)

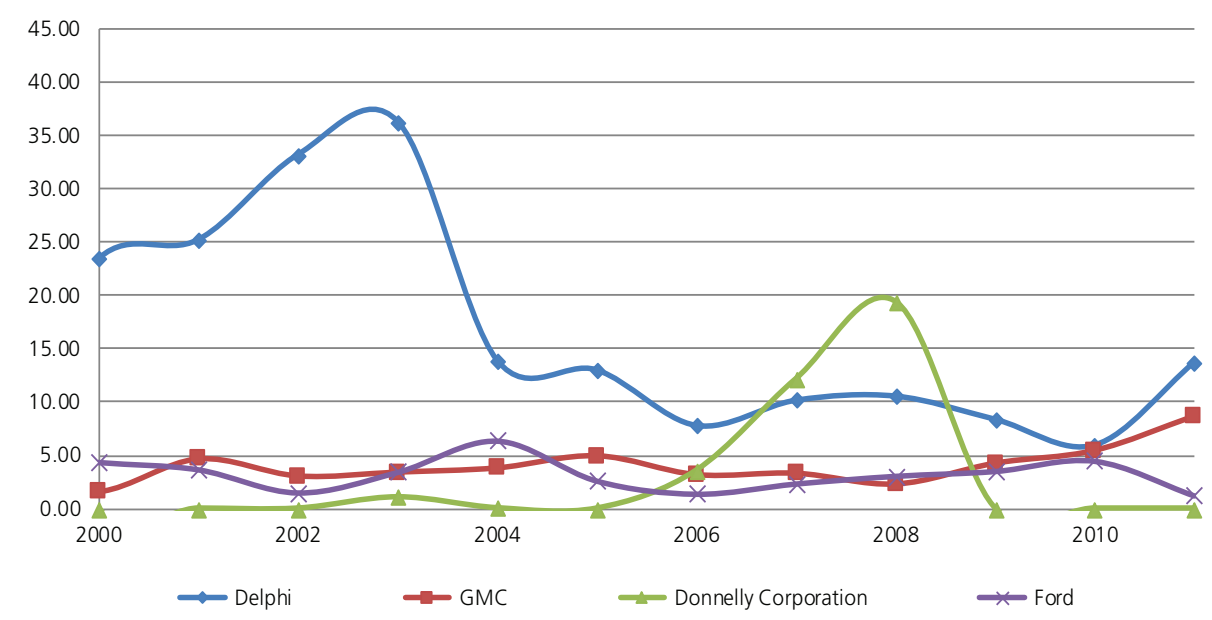

Fuente: Elaboración propia con base en datos de uspto.

\section{MÉXICO Y SU LUGAR EN LA EXPLORACIÓN Y EXPLOTACIÓN DE LA EMPRESA DELPHI}

Como se mencionó en el segundo apartado de este trabajo existe un creciente número de ingenieros trabajando en el Centro Técnico de Servicios, en esa dirección este apartado se centra en la posición de los inventores de Delphi y específicamente los de residencia mexicana.

En el caso de las patentes de Delphi se encontraron inventores con residencia en 27 países diferentes, en su mayor medida en Estados Unidos. En la gráfica 4 se muestra el número promedio de inventores según su residencia, si se encuentra o no en Estados Unidos. En el primer periodo (1995-1999), se observa que en promedio había más inventores con residencia no estadounidense, por ejemplo, en 1995 había un inventor con residencia externa a Estados Unidos por patente, en 1997 había tres. En cambio, en ese mismo año existía la mitad de inventores estadounidenses. Este promedio es muy inestable debido al número reducido de patentes de dicho periodo. Pero una vez que empieza a crecer el esfuerzo inventivo existe una diferencia sustancial entre aquellos con residencia norteamericana y el resto. Para el año 2000, había 2.5 inventores con residencia estadounidense por patente, contra 0.3 inventores con residencia no estadounidense. Este último número ha ido creciendo constantemente hasta llegar a un inventor no residente en Estados Unidos por patente en 2014, contra 1.8 de residentes en el 
mismo año. Esto determina que si bien el número de no residentes ha ido en aumento, la base de recursos humanos especializados sigue localizada sustancialmente en dicho país.

En lo que respecta a la residencia de los inventores de Estados Unidos, alrededor de 93 por ciento (del total de las apariciones de inventores residentes en ese país) tiene residencia en cuatro estados (de un total de 36) en específico: Michigan (36 por ciento), Indiana (23 por ciento), Nueva York (17 por ciento) y Ohio (17 por ciento) y, muy por debajo aparece Texas (3 por ciento). La gráfica 5 muestra la evolución de la residencia de estos inventores, para el caso de los residentes de Michigan, lugar que por un largo periodo se encontraba la sede de Delphi, también era la principal residencia de los inventores. En el año 2000, había 0.9 inventores por patente con residencia en Michigan. Este número varió poco hasta 2008 (un inventor de Michigan por patente). Después se ha ido reduciendo hasta 0.3 en 2014. Para el caso de los residentes de Indiana su participación ha ido en incremento, en el 2000 había 0.4 residentes de Indiana por patente hasta que en 2013 llegó a un residente por patente. En lo que respecta a los residentes de Ohio y Nueva York la tendencia no es clara pues ha tenido muchas oscilaciones.

Gráfica 4. Número de inventores según residencia, 1995-2014

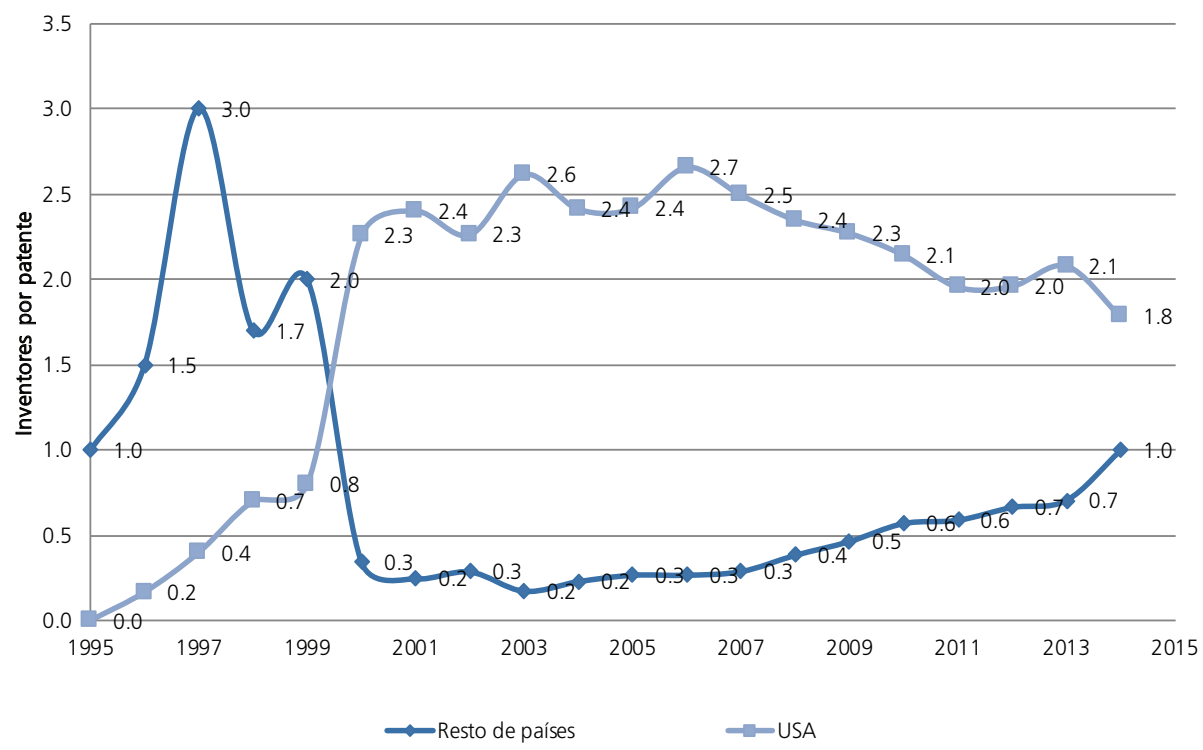

Fuente: Elaboración propia con base en datos de usPTO. 
Gráfica 5. Inventores por patente con residencia en Estados Unidos.

\section{Principales estados, 2000-2014}

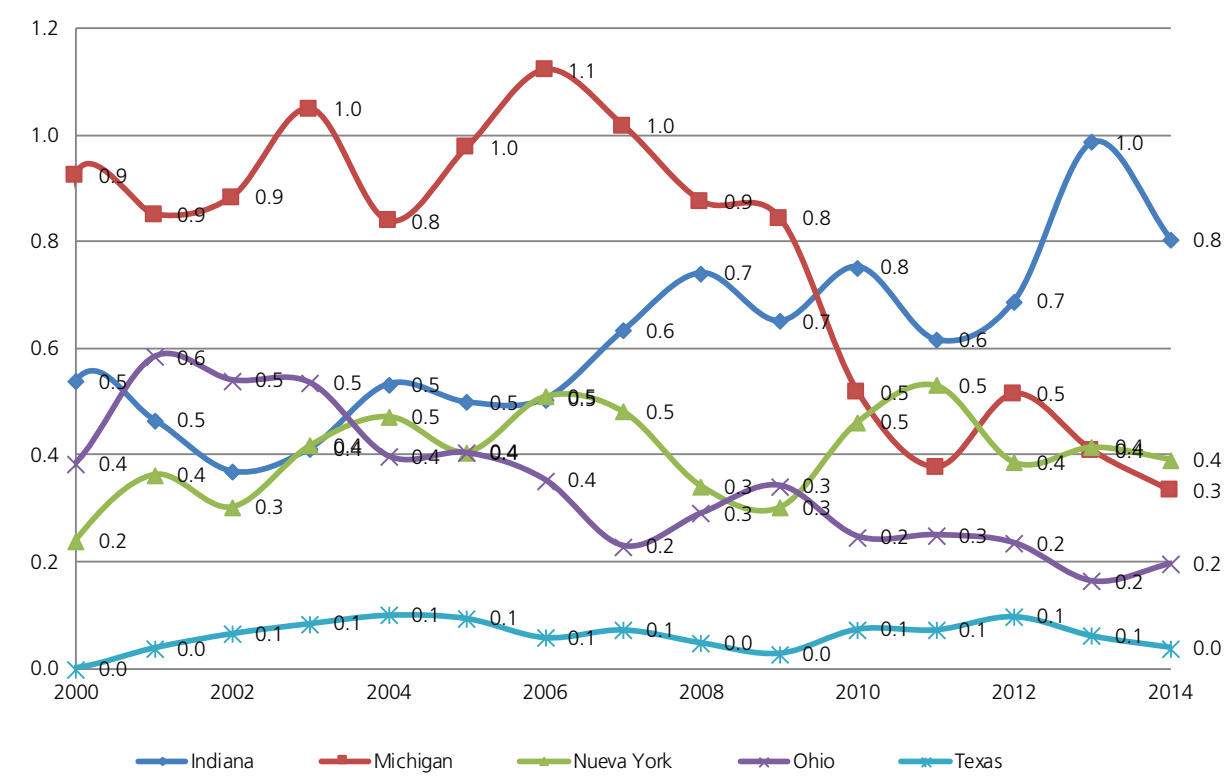

Fuente: Elaboración propia con base en datos de uspTo.

Lo que destaca es que los tres estados son cercanos a Michigan, noreste del vecino país, dueños de una larga historia automotriz. Por último, aparece Texas con una muy reducida participación por patente, sin embargo, al ser frontera con Ciudad Juárez, México, destaca su participación para el caso mexicano.

En lo que respecta al resto de países de residencia de los inventores de Delphi (el "resto" en la gráfica 4), se mencionaba que existe registro de 26 diferentes países de residencia. Los que tienen más presencia son presentados en la gráfica 6: Francia, Reino Unido, Alemania, China, Bélgica, Corea, México y Singapur. La gráfica expone el número de inventores por patente, según su residencia. Se puede apreciar que en la mayoría de los países de residencia no existe una tendencia clara en su participación. Sin embargo tres países resaltan: Alemania, Reino Unido y Francia. Para el año 2000, en una de cada cuatro patentes había un inventor con residencia alemana ${ }^{18}$, este número decreció en los siguientes años y empezó

${ }^{18} \mathrm{El}$ indicador muestra 0.24 y como no podemos tener un 0.24 de inventor entonces se cierra a .25 y .25 de un inventor con residencia alemana sumaría 1 cuando se tenga 4 patentes. 


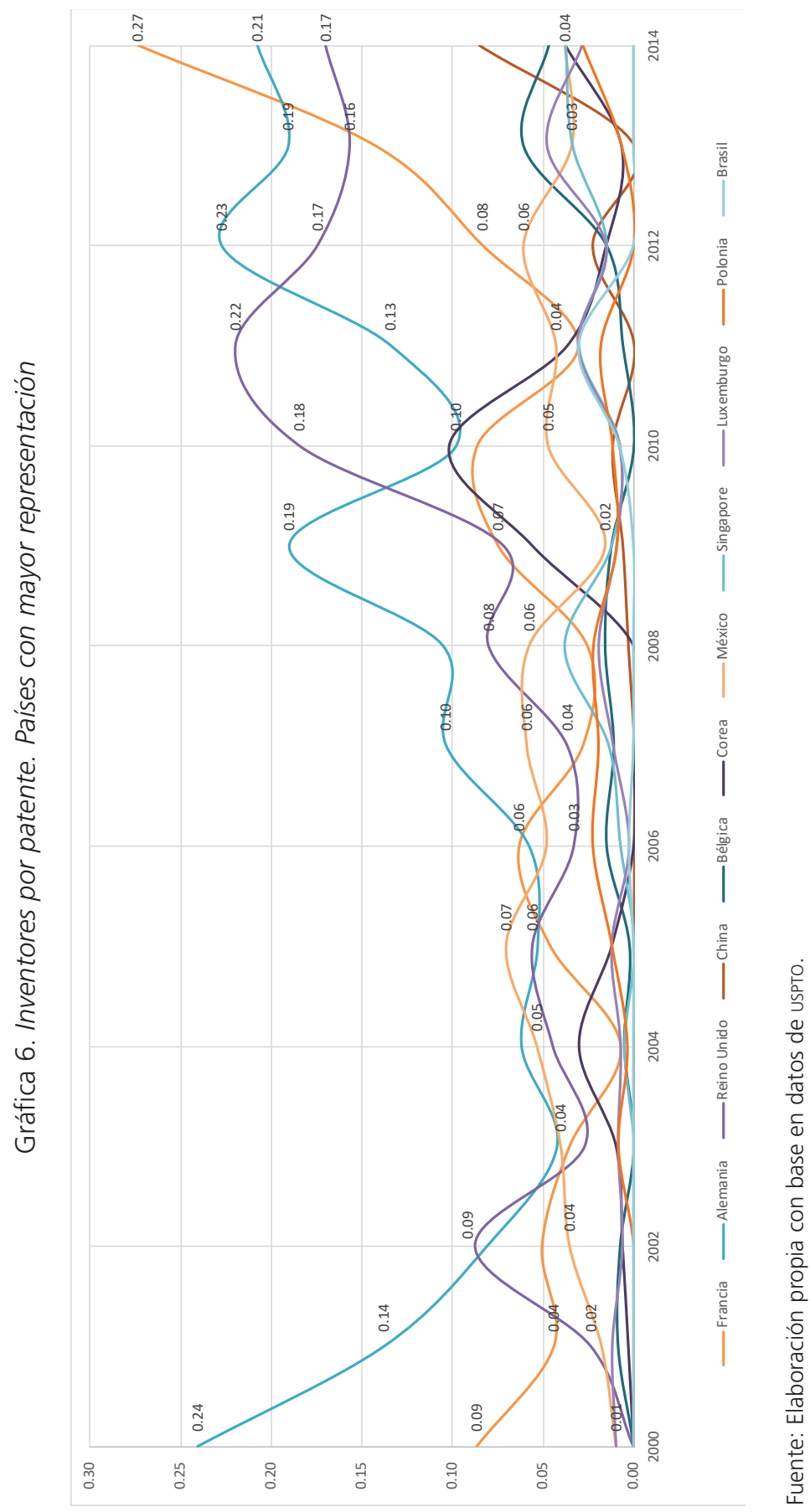


a crecer para 2006, hasta llegar a 0.21 en el 2014, esto se traduciría como un inventor con residencia alemana cada cinco patentes. En el caso de residentes franceses, para el 2014 aparecían en una de cada cuatro patentes (0.27), esta tendencia fue creciendo principalmente desde 2010. Los residentes del Reino Unido a partir de 2008 tienen una mayor presencia, en 2014, en una de cada seis patentes había un residente inglés.

Para el caso específico de residentes mexicanos, en el año 2000, había un inventor con residencia mexicana por cada 100 patentes. Este número osciló, pero no sobrepasó el número de uno cada 20 patentes en 2011 (0.05). Dichos inventores aparecen en 214 patentes de Delphi, específicamente son 84 inventores, de los cuales 74 se localizaban en Ciudad Juárez, Chihuahua, frontera con El Paso, Texas. Se tomaron dichas patentes y se consideró ver quién está aprovechando dichos conocimientos, aunque ya se había mencionado y no se esperaba que hubiera agentes mexicanos que lo hicieran, esto se hace para recalcar la dinámica en la que se encuentran inmersos dichos inventores.

Se encontró que dichas patentes habían recibido 462 citas de 170 empresas y de 18 países (58 por ciento de las citas son de empresas estadounidenses, 18 por ciento de japonesas y 13 por ciento alemanas, el resto, de otros 15 países). Se destaca que, de esas 91 son auto-citas (20 por ciento), 13 citas ( 3 por ciento) de Cameron International, Denso y Trico, respectivamente, después el restante con menos de 9 citas cada una.

En aras de conocer si la generación de estos conocimientos expresados en patentes por inventores con residencia en México había traído consigo beneficios independientes a Delphi, como por ejemplo, nuevas empresas para dichos inventores, se buscó si tenían patentes independientemente de las que tenían en Delphi. De los 84 inventores, 18 tenían patentes, de ésos, 14 tenían patentes registradas en empresas con residencia extranjera. Los restantes cuatro tienen registro de patentes de forma individual (no recurrieron a una empresa), tres de ellos aparecen con residencia norteamericana.

Como se aprecia, no existe prueba de que existan al nivel de inventores spillovers tecnológicos que impacten de forma positiva (generación de conocimientos para nuevas empresas, o invenciones de los inventores que no correspondan únicamente a lo desarrollado por Delphi).

\section{CONSIDERACIONES FINALES}

Delphi ha tenido una estrategia de relocalización de su producción, sin embargo, no ha sido a la par, o a la misma velocidad que la relocalización de generación de conocimiento tecnológico. Al menos eso es lo mostrado con la información tecno- 
lógica arriba expuesta. Eso habla también de la explotación de lo ya aprendido y de quién lo ha aprendido, recursos humanos ya existentes principalmente en la región de Michigan.

Más allá de la inexistencia de los spillovers en México que se evidencia en el presente trabajo, se muestra que existen dos mecanismos que evitan dichos spillovers tecnológicos: 1) la dinámica de la empresa en la que se ha especializado que parece ajena a la dinámica nacional, ya que con 20 años de haber instalado el primer Centro Técnico Delphi en México no han aparecido los spillovers tecnológicos; 2) por otro lado, existe una alta competencia para aprovechar los conocimientos de Delphi, en ese sentido, sólo las empresas con cierta especialización, capacidad técnica y económica pueden retener el conocimiento antes de que entren en depreciación.

En resumen, se muestra incapacidad (y al parecer incentivos al ser tan especializada la producción) por parte de empresas mexicanas de aprovechar (spillovers) el conocimiento de Delphi, explorar el conocimiento altamente especializado de la empresa podría ser riesgoso y podría encontrarse relativamente fuera de la vecindad tecnológica nacional (además de barreras a la entrada existentes como la capacidad de capital necesaria y de conocimiento logístico). De esa forma se podría conocer que quien aprovecha los conocimientos que genera Delphi es en gran medida la competencia y los clientes, hasta ahora no mexicanos (esto no niega la existencia de algunos ya importantes como el caso de empresas situadas en Nuevo León, México).

Se añade, que, aun cuando la participación de inventores no residentes en Estados Unidos es creciente (con información en la oficina de patentes de Estados Unidos) también es limitada respecto al total de inventores de Delphi, en ese sentido fue importante subrayar en el primer apartado los aspectos internacionales de la empresa. Lo mismo obedece para el caso de los inventores mexicanos, que aunque participan con un importante número de patentes, no han podido tener efectos positivos como spillovers de tecnológicos.

En cuanto a la literatura que enmarca a Delphi como una maquiladora de cuarta generación, habría que complementar que sus spillovers tecnológicos son inexistentes, por lo que se observa a Delphi más como un enclave, que como un generador de derramas tecnológicas, que, como se mencionó, sólo pueden ser explotadas por la empresa, y exploradas por la competencia.

El estudio también propone una metodología para el estudio de los spillovers, que se basó en dos elementos: 1) los conceptos de explotación, exploración y spillovers de conocimientos, lo que permitió observar la dinámica de las empresas que generan conocimientos tecnológicos, y de qué forma aprovechan los conocimientos tecnológicos y otros lo toman (externalidades positivas o 
negativas); 2) el uso de patentes y su citas, lo que permiten operacionalizar los conceptos enunciados.

Por último, es importante destacar que el estudio tiene una limitación al sólo tomar las patentes y sus citas para el estudio de los spillovers, ya que únicamente representarían un proxy de los mismos.

\section{REFERENCIAS BIBLIOGRÁFICAS}

Albert, M. B.; Avery, D.; Narin, F. y McAllister, P. (1991), "Direct validation of citation counts as indicators of industrially important patents", Research Policy, 20, pp. 251-259.

Alcácer, Juan y Minyuan, Zhao (2010), "Local R\&D Strategies and Multi-location Firms: The Role of Internal Linkages", Management Science, 58 (4), pp. 734-753.

Alcácer, Juan y Wilbur, Chung (2007), "Location Strategies and Knowledge Spillovers", Management Science, 53 (5), pp. 760-776.

Anderson, Philip y Tushman, Michael L. (1990), "Technological Discontinuities and Dominant Designs: A Cyclical Model of Technological Change", Administrative Science Quarterly, 35 (4), pp. 604-633.

Arias, Aryenis (2004), Capacidades innovadoras en la Industria Maquiladora de Exportación en México. El caso de DELPHI CORP. Una empresa proveedora del sector automotriz, tesis de maestría, México, UAM, [en línea], disponible en: http://dcsh.xoc.uam.mx/ecocambiotec/TESIS_DOCTORADO/ Arias_Navarro_Aryenis.PDF. [Consultada el 5 de junio de 2015].

Arias, Aryenis y Dutrenit, Gabriela (2003), “Acumulación de capacidades tecnológicas locales de empresas globales en México: El caso del Centro Técnico de Delphi Corp", Revista Iberoamericana de Ciencia, Tecnología, Sociedad e Innovación, 6, [en línea], disponible en: http://www.oei.es/ revistactsi/numero6/articulo02.html

Arthur, William B. (1994), Increasing returns and path dependence in the economy, Michigan, The University of Michigan Press.

Bernard, Andrew B. y Bradford, Jensen J. (1999), "Exceptional exporter performance: cause, effect, or both?", Journal of International Economics, 47 (1), pp. 1-25.

Blomström, Magnus y Kokko, Ari (1998), "Multinational Coporations and Spillovers", Journal of Economic Surveys, 12 (3), pp. 247-277. 
Bottazzi, Laura y Peri, Giovanni (2007), "The international dynamics of R\&D and innovation in the long run and in the short run", The Economic Journal, 117, pp. 486-511.

Branstetter, Lee (2006), "Is foreign direct investment a channel of knowledge spillover? Evidence from Japan's FDI in the United States", Journal of International Economics, 68, pp. 325-344.

Cantwell, John A. y Lucia, Piscitello (2003), "The Recent Location of Foreign R\&D Activities by Large MNCs in the European Regions. The Role of Different Sources of Spillovers", ponencia presentada en el 43rd ERSA Congress, Jyväskylä Finlandia.

Carrillo, Jorge y Hualde, Alfredo (1997a), "Delphi-General Motors: ¿Centro de investigación y desarrollo o maquiladora de alta tecnología?", ANAIS, Seminario Internacional Educacão Professional, Trabalho e Competencias, Río de Janeiro, 1996, pp. 35-52. (1997b), "Maquiladoras de tercera generación. El caso de Delphi-General Motors", Comercio Exterior, 47 (9), pp. 747-757.

Carrillo, Jorge y Lara, Arturo (2004), "Nuevas capacidades de coordinación centralizada. ¿Maquiladoras de cuarta generación en México?”, Estudios Sociológicos, 22 (3), pp. 647-667.

Carrillo, Jorge (2007), "La industria maquiladora en México: ¿evolución o agotamiento?", Comercio Exterior, 57 (8), pp. 668-681.

Coe, David T. y Helpman, Elhanan (1995), "International R\&D spillovers", European Economic Review, 39, pp. 859-887.

Cohen, Wesley M. y Levinthal, Daniel (1990), "Absorptive capacity: a new perspective on learning and innovation", Administrative Science Quarterly, 35 (1), pp. 128-152.

Comanor, William S., y Scherer, Frederic M. (1969), "Patent statistics as a measure of technical change", Journal of Political Economy, 77 (3), pp. 392-98.

Covarrubias, Alex (2014), Explosión de la industria automotriz en México: de sus encadenamientos actuales a su potencial transformador, Friedrich Ebert Stiftung 1, p. 44.

Covarrubias, Alex y Arteaga-García (2015), La industria automotriz en México, frente al nuevo siglo, México, El Colegio de Sonora, Universidad Autónoma Metropolitana, Miguel Ángel Porrúa.

Delphi (2009), 2008 Consolidated financial statements Delphi Automotive LLP, [en línea], disponible en http://library.corporate-ir.net/library/10/105/105758/items/327071/3A0E57E4-29A8-4825-9594- 
115FD65E4940_2008\%2010-K20FINAL.pdf. [Consultado el 10 de septiembre de 2015].

(2010), 2009 Consolidated financial statements Delphi Automotive LLP, [en línea], disponible en: http://s2.q4cdn.com/607989273/files/doc_ downloads/llp_financial $/ 2010 \% 20$ Year $\% 20 \mathrm{End} \% 20$ Financial $\% 20$ Statement.pdf. [Consultado el 10 de septiembre de 2015]. (2011), 2010 Annual Review, [en línea], disponible en: http://www.delphi.com/. [Consultado el 10 de septiembre de 2015]

(2012), 2011Annual Review, [en línea], Disponible en: http://www.delphi.com/. [Consultado el 10 de septiembre de 2015]. (2013), 2012 Consolidated financial statements Delphi Automotive LLP, [en linea], disponoble en: http://www.sec.gov/Archives/edgar/data/1521332/000152133213000010/dlph1231201210k.htm. [Consultado el 10 de septiembre de 2015]. (2014), 2013 Annual Report, [en línea], disponible en: http://investor. delphi.com/investors/financial-information/annual-reports/default.aspx. [Consultado el 10 de septiembre de 2015]. (2015), 2014 Annual Report, [en línea], disponible en: http://investor. delphi.com/investors/financial-information/annual-reports/default.aspx. [Consultado el 10 de septiembre de 2015].

(2016), 2015 Annual Report, [en línea], disponible en: http://investor. delphi.com/investors/financial-information/annual-reports/default.aspx. [Consultado el 2 de enero de 2016].

Eldredge, Niles y Gould, Stephan J. (1972), "Speciation and punctuated equilibria: an alternative to phyletic gradualism", en Schopf, Tom J. M. (coord.), Models in paleobiology, Freeman, Cooper \& Co, San Francisco, pp. 99115 .

(1977), "Punctuated equilibria: the tempo and mode of evolution reconsidered", Paleontobiology, 3 (2), pp. 115-155.

Fleming, Lee y Sorenson, Olav (2001), "Technology as a complex adaptive system: Evidence from patent data", Research Policy Forthcoming, 30 (7), pp. 1019-1039.

Fleming, Lee; King, Charles III y Juda, Adam I. (2007), “Smalls Worlds and Regional Innovations”, Organization Science, 18 (6), pp. 938-954.

García, Alejandro y Reyes, Juan (2015), "Patentamiento, trayectoria y características de las baterías automotrices: el caso de los autos híbridos", Entreciencias, 3 (6), pp. 41-56. 
Garza, Enrique de la (2013), “Alternativas al modelo maquilador”, en Oropeza, Arturo (comp.), México Frente a la Tercera Revolución Industrial, México, UNAM-Instituto de Investigaciones Jurídicas, pp. 489-508.

Geisler, Eliezer (2000), The Metrics of Science and Technology, Wesport CT and London, Quorum.

Gutiérrez, Hector (2013), Oportunidades de crecimiento y de desarrollo de la Industria Maquiladora de Exportación. Delphi México, [en línea], disponible en: http://www.imef.org.mx/descargas/2013/CdJuarez/HectorG. pdf. [Consultado el 10 de septiembre de 2015].

Goel, Rajeev K. (1995), “Spillovers, Rivalry and R\&D Investment”, Southern Economic Journal, 62 (1), pp. 71-76.

Griliches Z (1979), "Issues in assessing the contribution of research and development to productivity growth", Bell Journal of Economics, 10 (1), pp. 92-116.

Griliches, Zvi (1990), "Patent Statistics as Economic Indicators: A Survey”, Journal of Economic Literature, American Economic Association, 28 (4), pp. 1661-1707.

(1998), "Issues in Assessing the Contribution of Research and Development to Productivity Growth", en Griliches Zvi (ed.), R\&D and Productivity: The Econometric Evidence), University of Chicago Press, pp. 17-45.

Hall, Bronwyn H.; Jaffe, Adam y Trajtenberg, Manuel (2001), “The NBER Patent citation data file: Lessons, insights and Methodological Tools", NBER Working Paper 8498 [en línea], disponible en: http://www.nber.org/papers/w8498. [Consultado en septiembre de 2010].

He, Ze-Lin, y Wong, Poh-Kam (2004), "Exploration vs. exploitation: An empirical test of the ambidexterity hypothesis", Organization Science, 15 (4), pp. 481-494.

$\mathrm{Hu}$, Alberth, y Jaffe, Adam B. (2003), "Patent citations and international knowledge flow: the cases of Korea and Taiwan", International Journal of Industrial Organization, 21 (6), pp. 849-880.

Jaffe, Adam B. (1984), “The Effects of Market Demand, Technological Opportunity and Research Spillovers and R\&D Intensity and Productivity Growth", NBER Working Paper, pp. 1432, 1-52.

(1986), "Technological opportunity and spillovers of R\&D: evidence from firms' patents, profits, and market value", American Economic Review, 76, pp. 984-1001. 
Jaffe, Adam B. y Trajtenberg, Manuel (1998), "International Knowledge Flows: Evidence From Patent Citation", NBER Working Paper 6507 [en línea] disponible en: http://www.nber.org/papers/w6507. [Consultado en septiembre 2010].

Jaffe, Adam B.; Trajtenberg, Manuel y Fogarty, Michael S. (2000), "Knowledge Spillovers and Patent Citations: Evidence from a Survey of Inventors", American Economic Review, 90 (2), pp. 215-218.

Jaffe, Adam B.; Trajtenberg, Manuel y Henderson, Rebeca (1993), "Geographic Localization of Knowledge Spillovers as Evidence by Patent Citations", The Quarterly Journal of Economis, 10 (3), pp. 577-598.

Juárez, Huberto (2010), "La industria del automóvil en México, perspectivas para 2010", Metapolítica: la mirada limpia de la política, 69, pp. 15001565.

Kokko, Ari (1994), “Technology, Market Characteristics, and Spillovers”, Journal of Development Economics, 43 (2), pp. 279-293.

Kuemmerle, Ruediger W. (1997), "Building effective R\&D capabilities abroad", Harvard Business School, 75 (2), pp. 61-70.

Laffont, Jean J. (1993), A Theory of Incentives in Procurement and Regulation, Cambridge, MIT Press.

Lara, Arturo (2000), "Convergencia tecnológica y maquila de tercera generación: el caso de Delphi Juárez”, Comercio Exterior, 50 (9), pp. 771-780.

Lee, Keun (2013), Schumpeterian Analysis of Economic Catch-up Knowledge, Path-Creation, and the Middle-Income Trap, Cambridge, University Press.

Levinthal, Daniel A. y March, James G. (1993), “The Myopia of Learning”, Strategic Management Journal, 14, pp. 95-112.

Levinthal, Daniel A. (1998), "The Slow Pace of Rapid Technological Change: Gradualism and Punctuation in Technological Change", Industrial and Corporate Change, 7 (2), pp. 217-247.

Marshall, Alfred (1890), Principles of economics, Macmillan, London.

Meyer, Martin (2002), "Tracing knowledge flows in innovation systems", Scientometrics, 54 (2), pp. 193-212.

March, James G. (1991), "Exploration and Exploitation in Organizational Learning”, Organization Science, 2 (1), pp. 71-87.

Montobbio, Fabio (2007), Patenting activity in Latin American and Caribbean countries. Reporte para proyecto: Study on intellectual property management in open economies: a strategic vision for Latin America, Organi- 
zación Mundial de la Propiedad Industrial y Comisión Económica para América Latina y el Caribe.

Montobbio, Fabio y Sterzi, Valerio (2011), "Inventing together: exploring the nature of international knowledge spillovers in Latin America", Journal of Evolutionary Economics, 21, pp. 53-89.

Nooteboom, Bart (2000), Learning and innovation in organizations and economies, Reino Unido, Oxford University.

(2009), A Cognitive Theory of the Firm. Learning, Governance and Dynamic Capabilities, Edward Elgar, Cheltenham.

Nooteboom, Bart y Stam, Erik (2008), Microfoundations for innovation policy, Amsterdam, Chicago University Press.

oCDE (2005), Manual de Oslo. Guía para la recogida e interpretación de datos sobre innovación, TRAGSA.

Page, Scott E. (2011), Diversity and Complexity, Princeton, Princeton University Press.

Pavitt, Keith (1984), "Sectoral patterns of technical change: towards a taxonomy and a theory", Research Policy, 13 (6), pp. 343-373.

Pesola, Hanna (2007), "Foreign ownership, labour mobility and wages", HEER, Helsinki Centre of Economic Research, Discussion Paper, 175, pp. 1-30.

Pigou, Arthur C. (1920), The economics of welfare, Londres, Macmillan.

Pisano, Gary P. (2012), "Creating an R\&D Strategy", Working Papers Harvard Business Review, 12 (195), pp. 1-10.

ProMéxico (2013), Industria Terminal Automotriz, Unidad de Inteligencia de Negocios, Secretaría de Energía, Gobierno de la República.

Ramírez, Hilda y Correa, María Antonia (2002), "Ventaja competitiva de Delphi Automotive System sobre Yazaki Corporation”, Adminstración y Organizaciones, 8 (4), pp. 77-88.

Reyes, Juan (2016), "Diversidad en el sector tecnológico de baterías. Una propuesta metodológica basada en la medición de entropía con patentes", Economía Informa, 401, pp. 60-84.

Schmookler, Jacob (1954), "The level of Inventive Activity", Review Economic Static, 36 (2), pp. 183-190.

Scherngell, Thimas y Jansenberger, Eva (2006), "Patents, Patent Citations and the Geography of Knowledge Spillovers in Europe", en Fisher, Manfred (coord.), Innovation, Networks, and Knowledge Spillovers (2006), Viena, Springer. 
74 ECONOMÍA TeOría y PRÁCTICA • Nueva Época, número 48, enero-junio 2018

Scitovsky, Tibor (1954), "Two concepts of external economies", Journal of Political Economy, 62, pp. 70-82.

Sorensen, Olav; Rivkin Jan W. y Fleeming, Lee (2002), "Complexity, Networks and Knowledge Flow", Research Policy, 35 (7), pp. 994-1001.

United States Patent and Trademark Office's (2015), [en línea], disponible en: www.uspto.gov. [Consultado en enero de 2015]. 